\title{
Estimation of the Influence of Compressed Hydrogen on the Mechanical Properties of Pipeline Steels
}

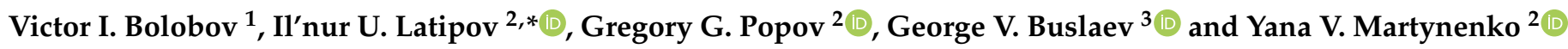 \\ 1 Faculty of Mechanical Engineering, St. Petersburg Mining University, 2, 21st Line, \\ 199106 St. Petersburg, Russia; boloboff@mail.ru \\ 2 Department of Transport and Storage of Oil and Gas, Faculty of Oil and Gas Engineering, St. Petersburg \\ Mining University, 2, 21st Line, 199106 St. Petersburg, Russia; Genrih-91@mail.ru (G.G.P.); \\ y.v.martynenko@mail.ru (Y.V.M.) \\ 3 Department of Well Drilling, Faculty of Oil and Gas Engineering, St. Petersburg Mining University, 2, 21st \\ Line, 199106 St. Petersburg, Russia; Buslaev_GV@pers.spmi.ru \\ * Correspondence: latipoviu@gmail.com
}

check for updates

Citation: Bolobov, V.I.; Latipov, I.U.; Popov, G.G.; Buslaev, G.V.;

Martynenko, Y.V. Estimation of the Influence of Compressed Hydrogen on the Mechanical Properties of Pipeline Steels. Energies 2021, 14, 6085 https://doi.org/10.3390/en14196085

Academic Editor: Attilio Converti

Received: 27 July 2021

Accepted: 20 September 2021

Published: 24 September 2021

Publisher's Note: MDPI stays neutral with regard to jurisdictional claims in published maps and institutional affiliations.

Copyright: (c) 2021 by the authors. Licensee MDPI, Basel, Switzerland. This article is an open access article distributed under the terms and conditions of the Creative Commons Attribution (CC BY) license (https:/ / creativecommons.org/licenses/by/ $4.0 /)$.

\begin{abstract}
Consideration of the possibility of transporting compressed hydrogen through existing gas pipelines leads to the need to study the regularities of the effect of hydrogen on the mechanical properties of steels in relation to the conditions of their operation in pipelines (operating pressure range, stress state of the pipe metal, etc.). This article provides an overview of the types of influence of hydrogen on the mechanical properties of steels, including those used for the manufacture of pipelines. The effect of elastic and plastic deformations on the intensity of hydrogen saturation of steels and changes in their strength and plastic deformations is analyzed. An assessment of the potential losses of transported hydrogen through the pipeline wall as a result of diffusion has been made. The main issues that need to be solved for the development of a scientifically grounded conclusion on the possibility of using existing gas pipelines for the transportation of compressed hydrogen are outlined.
\end{abstract}

Keywords: compressed hydrogen; hydrogen embrittlement; pipeline steels; mechanical properties

\section{Introduction}

Recently, research activities have intensified in the global industry and academia in anticipation of the upcoming European Green Deal implementation of measures aimed at minimizing greenhouse gas emissions into the atmosphere and creating a carbon-neutral zone in Europe by 2050. In the EU countries, there is a public demand that requires industrialists to minimize the technogenic impact on climatic processes. In this regard, with government support, initiatives are being developed that are entirely aimed at the formation of environmentally oriented strategies in the models of the activities of industrial enterprises.

The implementation of the targets of the "Green Deal" is impossible without the transformation of the energy sector of the countries of the European Union (EU) and the Asia-Pacific Region (APR), which involves the large-scale development of renewable energy sources (RES), as well as strengthening the role of alternative fuels, primarily hydrogen. Within the framework of minimizing the anthropogenic impact on the planet's ecosystem [1] and reducing greenhouse gas emissions [2] in various countries of the world, including Russia, it is assumed that hydrogen will be widely used as a fuel [3-5], as a widespread and ecologically safe type of fuel [6,7].

At the same time, hydrogen is considered as a secondary energy carrier, the advantage of which is the absence of a carbon footprint when it is used as a chemical raw material, as a source of electrical energy in fuel cells, or when it is burned in internal combustion engines or heating boilers. 
Fossil resources are considered as the primary source of energy, as well as renewable low-carbon energy sources (hydropower, wind energy, solar energy, etc.).

Fossil carbon-containing primary energy sources are considered as a transitional option, provided that carbon and its derivatives are utilized, preventing its release into the atmosphere. Because of this, it is advisable to locate facilities for producing low-carbon hydrogen from fossil primary sources in the immediate vicinity of the infrastructure for the utilization of $\mathrm{CO}_{2}$. In turn, renewable energy sources and electrolyzers are also advisable to be located in places with favorable conditions in order to achieve maximum efficiency.

Thus, consideration of hydrogen as a universal secondary energy carrier is impossible without solving the problems of its transport from the place of production to the place of use or a filling station.

Currently, the following methods of hydrogen transportation are used:

- in a gaseous state in cylinders and pipeline transport [8];

- in liquid [9-12];

- in a bound form using solid or liquid carriers $[13,14]$, including by land transport in cylindrical containers $[15,16]$.

At the same time, for the transportation of significant amounts of hydrogen, the most economically feasible is its transportation in a compressed state through pipelines [17-20]. In this regard, the possibilities of creating specialized pipeline systems for transporting hydrogen are being studied, however, as economic calculations show [21], the creation of such systems will be economically justified only when the market share of hydrogen energy reaches at least $10 \%$.

In this regard, the most acceptable option is the transportation of hydrogen through existing steel gas pipelines designed for pumping natural gas, the practical implementation of which is hampered by a number of unsolved technical problems, ranging from the possibility of pipeline explosion [17] and ending with its destruction due to the possible negative impact of hydrogen on mechanical properties of the pipe material [22,23], as well as significant losses arising when pumping compressed hydrogen through a pipeline [24]. In this regard, studies aimed at solving these problems are highly relevant.

Within the framework of this work, the possible states of hydrogen in metals are analyzed and the effect on the mechanical properties of steels of hydrogen is assessed, both inside the metal-"internal" and its surroundings- "external" [25], as well as estimates of the amount of hydrogen losses due to its diffusion of hydrogen through the wall of the pipeline.

The result of the work is the identification of the main issues that need to be resolved in order to develop a scientifically grounded conclusion on the possibility of using existing gas pipelines for the transportation of compressed hydrogen.

\section{The Process of Hydrogen Penetration into Metals}

The process of hydrogen penetration into metal from the gas phase can be divided into the following stages [26]:

- condensation of gaseous hydrogen on the metal surface, i.e., physical adsorption (controlled by van der Waals or dispersive forces);

- dissociation of molecules into separate atoms (activated adsorption, chemisorption);

- transition of atoms through the metal surface (gas dissolution in the metal);

- diffusion of hydrogen atoms from the surface into the interior of the metal [27].

The total rate of hydrogen penetration into the metal is determined by the slowest of these stages, which is determined by the process conditions.

At low pressures of gaseous hydrogen, the slowest stage is the adsorption of hydrogen molecules on the metal surface. In this case, according to the Langmuir adsorption isotherm, the fraction of the surface capable of retaining adsorbed hydrogen molecules is directly proportional to its partial pressure in the gas phase. In this case, the adsorbed molecules are not bound to certain places on the surface and are able to move along it [28]. 
In the process of dissociation of molecules (second stage), the formed atoms are bound by chemical forces with the atoms of the metal surface, which is largely explained by the fact that the valence of atoms on the metal surface is not completely saturated. Therefore, we can talk about the chemical interaction between gas molecules and metal atoms, which leads to dissociation and destruction of the gas molecule, while adsorption has a large thermal effect [28].

This process of dissociation of adsorbed molecules into atoms is limiting at sufficiently low temperatures.

At elevated temperatures and pressures, i.e., when a sufficient concentration of atomic hydrogen is created on the surface, the penetration rate and permeability are determined by the hydrogen diffusion parameters. This is confirmed by the direct dependence of the rate of hydrogen penetration through a metal barrier on the thickness of the barrier.

When metals are saturated with hydrogen during various electrolytic operations (electroplating, etching), hydrogen enters the metal surface in an ionized state, where the reaction takes place:

$$
\mathrm{H}^{+}+e \leftrightarrow \mathrm{H}
$$

Part of the formed hydrogen atoms combine into molecules with a transition to a gaseous state, and the other part is adsorbed by the surface and passes into the metal. In this case, the use of the electrolytic method already at room temperature makes it possible to saturate the surface metals to very significant concentrations of dissolved hydrogen. This is explained by the fact that during the cathodic evolution of hydrogen, such a concentration of atomic hydrogen ions is created at the metal surface, which, according to the results, is equivalent to thousands of atmospheres of pressure of gaseous hydrogen at elevated temperatures [26].

Experiments on electrolytic saturation of steel with hydrogen at low temperatures confirm the conclusion that insufficient saturation of steel with hydrogen at the same low temperatures, but from the gas phase, is due not to the low mobility of hydrogen atoms in the crystal lattice of the metal, but to surface adsorption phenomena [26]. It can be concluded that under conditions of temperatures (up to $323 \mathrm{~K}$ ) typical for main pipelines, the limiting stage of the process of hydrogen penetration into the metal will be the dissociation of hydrogen molecules on the inner surface of the pipe.

According to [29], one of the factors accelerating the process of hydrogenation of metals even at relatively low temperatures is the discontinuity of the metal (cracks, microfracture) with the formation of fresh (juvenile) surfaces.

As follows from [30], another factor activating the saturation of the metal with atomic hydrogen is the metal being under mechanical stress. The paper presents the results of a series of experiments on electrolytic hydrogenation at different temperatures of plates made of low-alloy steel 5XHM (C 0.5-0.6\%; Mn, Cr 0.5-0.8\%; Ni 1.4-1.8\%) [31] after quenching and low tempering, under the action of loads of varying intensity, providing elastic bending of the plate. In each individual experiment, the time from the beginning of hydrogenation to the moment of plate breakage was measured. Observations have shown that the specified time decreases as the load acting on the plate and the hydrogenation temperature increase (Table 1). Thus, with an increase in the load from 300 to $800 \mathrm{~N}$ (2.7 times), the time to destruction of the plate at room temperature decreases from 1116 to 50 s, i.e., decreases 22 times.

Table 1. The arithmetic mean (from 20 experiments) values of time (in sec) to destruction of the plates, depending on the load and temperature of the experiment [30].

\begin{tabular}{ccccc}
\hline & & \multicolumn{3}{c}{ Temperature, ${ }^{\circ} \mathbf{C}$} \\
\cline { 3 - 5 } No. & Load (N) & $\mathbf{5}$ & $\mathbf{2 0}$ & $\mathbf{4 0}$ \\
\hline 1 & 300 & 1558 & 1116 & 745 \\
2 & 600 & 190 & 148 & 114 \\
3 & 800 & 66 & 50 & - \\
\hline
\end{tabular}




\section{State of Absorbed Hydrogen in Metals}

According to [26,32,33], absorbed (inside the metal, "internal") hydrogen in a metal material can exist in the following forms:

- a solid solution of interstitiality in the interstices of the crystal lattice of the base metal;

- $\quad$ hydride with base metal;

- chemical compounds with impurities;

- atoms adsorbed on the surface of micro-discontinuities of the crystal structure of the metal and particles of the second phases;

- molecules accumulating in pores, cracks, and other discontinuities.

Iron belongs to the group of non-hydride-forming metals, with direct interaction of hydrogen with which the hydride can be obtained only by a preparative (special) method [26].

Hydrogen in iron and alloys based on it can be found simultaneously, both in interstices of the crystal lattice in the form of atoms, and in pores and other discontinuities in the form of molecules, into which it can recombine from atoms [34]. The lower the density of the metal and the more defects and lattice discontinuities, the greater the amount of hydrogen absorbed by non-hydride-forming metals and the greater the fraction of the absorbed hydrogen is in the molecular form [35,36].

The ratio between the mass of hydrogen in the atomic and molecular states depends on the limiting solubility of hydrogen in a given metal, its actual concentration in the crystal lattice, and the partial pressure of hydrogen in the pores [37].

Since atomic hydrogen appearing in the cavities immediately turns into molecular, and the degree of dissociation of molecular hydrogen at low temperatures is very small, equilibrium under normal conditions may not occur and atomic hydrogen will all the time enter the cavity, where it will turn into molecular [35].

At high supersaturations with hydrogen in cavities and other discontinuities, high pressures can arise, leading to deformation and destruction of the metal. Thus, at elevated temperatures and sufficiently high hydrogen pressures in the gas phase in the case of non-hydride-forming metals such as iron, fractures along the grain boundaries are possible without the application of external forces, only under the influence of molecular hydrogen pressure in the pores [32,38].

The deformation of metals under the influence of molecular hydrogen pressure is accompanied by a change in a number of their properties-surface hardness [36], magnetic properties, clarity of X-ray interference lines, etc.

Since the molecular state of hydrogen is one of the forms of the existence of hydrogen in metals, Me-H alloys based on non-hydride-forming metals (iron) can be considered as two phases, consisting of a solid solution of hydrogen in the crystal lattice of the metal and the release of molecular hydrogen in the pores $[26,39]$. For different metals, the conditions and rate of release of molecular hydrogen are different.

Hydrogen is able to enter into chemical compounds with impurities contained in the metal, with the formation of new phases, for example, methane $\mathrm{CH}_{4}$ in steel, which are released mainly along the grain boundaries [34].

\section{Influence of "Internal" Hydrogen on the Mechanical Properties of Steels}

The effect of gaseous hydrogen on steel is its saturation with hydrogen ("hydrogenation"), accompanied by a change in the mechanical properties of the steel. The degree and intensity of hydrogenation are determined by the pressure of gaseous hydrogen, temperature, and composition (grade) of steel.

The solubility of hydrogen in iron, i.e., the maximum amount of hydrogen that can be in a metal in the form of a solid solution $(\mathrm{H})$ at room temperature and atmospheric pressure is $\sim 0.0001 \mathrm{~m}^{3} / 0.1 \mathrm{~kg} \mathrm{Fe}$ [26]. A large amount of hydrogen, measured in tens of cubic centimeters per $100 \mathrm{~g}$ of metal, can be introduced into steel from the gas phase only at high pressures and elevated temperatures [38]. The same intensity of saturation of steel with hydrogen is achieved at room temperature as a result of electrolytic evolution of 
hydrogen at the cathode, if the cross section of steel samples saturated with hydrogen is small [40]. At room temperature and normal pressure, the previously introduced "excess" hydrogen is gradually released from the steel.

As follows from data 2, the maximum service life of the cylinders under study at the time of the analysis of their materials was:

- 53 years at a pressure of $15 \times 106$ Pa for steel 45;

- 15 years at a pressure of $20 \times 106$ Pa for $38 \mathrm{KhA}$ steel;

- 8 years at a pressure of $32 \times 106$ Pa for 35 KhN3MFA steel.

Based on the test results of 6-9 samples cut from the middle of the wall thickness of the cylindrical part of each cylinder, the ability of steels to absorb hydrogen during operation and the effect of absorbed hydrogen on the mechanical and operational properties of the cylinder material were evaluated. The quantitative content of hydrogen in each sample was determined by the method of reducing melting.

The results of determining the hydrogen content in the cylinder material are illustrated in the diagrams in Figure 1. The height of each bar of the diagram column corresponds to the amount of hydrogen recorded in the corresponding sample cut from the cylinder wall after its operation for time $N$ at pressure $P_{w}$, given in Table 2 .

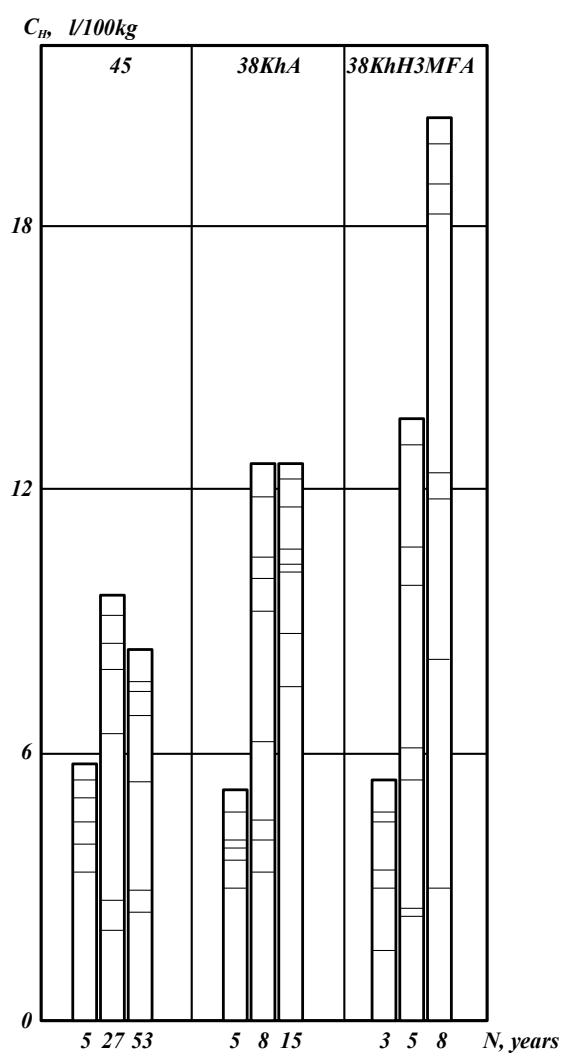

Figure 1. The amount of hydrogen in the samples, cut out from the walls of cylinders made of various steels, after the service life $N$ [41].

Based on the data in Figure 1, the authors of [41,42] conclude that during the operation of cylinders in a hydrogen gas environment, regardless of their material (medium carbon steel 45 or alloyed steels $38 \mathrm{KhA}$ and $35 \mathrm{KhN} 3 \mathrm{MFA}$ ) and its strength characteristics (steel 45 of medium strength, steel $35 \mathrm{KhN3MFA}$ - high) hydrogen is absorbed by the metal. Moreover, the higher the working pressure in the cylinder and the strength of its material, the more intense the process. It has been noted [42] that there is a directly proportional relationship between the average content of absorbed hydrogen in the metal on the duration of cylinder operation: the increase in the volume of adsorbed hydrogen for every 5 years of operation is $0.3 \times 10^{-6} \mathrm{~m}^{3} / 0.1 \mathrm{~kg}$ for steel 45 and 0.2 for steel $38 \mathrm{KhA}$. The large scatter 
of data obtained on the samples of each cylinder may indicate an uneven distribution of hydrogen in the volume of the metal.

Table 2. Chemical composition of materials [31] and parameters of the investigated hydrogen cylinders [41].

\begin{tabular}{|c|c|c|c|c|c|c|}
\hline \multirow{2}{*}{$\begin{array}{l}\text { Cylinder Material and } \\
\text { Chemical Composition, } \%\end{array}$} & \multirow{2}{*}{$P_{w} 10^{6}, \mathrm{~Pa}$} & \multirow{2}{*}{$V, \mathrm{~m}^{3}$} & \multicolumn{3}{|c|}{ Dimensions, $\mathrm{m}$} & \multirow{2}{*}{$N$, Years } \\
\hline & & & $D$ & $s$ & $L$ & \\
\hline $\begin{array}{c}\text { Steel } 45 \\
\text { (C 0.42-0.5; Mn 0.5-0.8;) }\end{array}$ & 15 & 0.04 & 0.219 & 0.007 & 1.37 & $\begin{array}{c}5 \\
27 \\
53\end{array}$ \\
\hline $\begin{array}{c}\text { Steel } 38 \mathrm{KhA} \\
\text { (C 0.35-0.42; Mn 0.25-0.5; } \\
\text { Cr 1.2-1.5; Ni 3-3.5) }\end{array}$ & 20 & 0.4 & 0.465 & 0.015 & 3.04 & $\begin{array}{c}5 \\
8 \\
15\end{array}$ \\
\hline $\begin{array}{c}\text { Steel } 35 \text { KhN3MFA } \\
\text { (C 0.33-0.40; Mn 0.50-0.80; } \\
\text { Cr 0.8-1.1) }\end{array}$ & 32 & 0.4 & 0.465 & 0.017 & 3.15 & $\begin{array}{l}3 \\
5 \\
8\end{array}$ \\
\hline
\end{tabular}

Designation: $P_{w}$-working pressure, $V$-volume, $D$-diameter, $s$-wall thickness, $L$-length, $N$-service life.

Table 3 shows the mechanical properties $\left(\sigma_{B}, \sigma_{T}, \delta_{5}\right)$ of the materials of these cylinders, obtained by stretching the samples to rupture in air in accordance with [43]. In the same place, for comparison, the values of the same characteristics are given, which are necessary to comply with the requirements of technical documentation [44-46] for materials of cylinders for storage and transportation of compressed, liquefied, and dissolved gases (working medium — nitrogen, ammonia, argon, butane, butylene, hydrogen, air, helium, oxygen, xenon).

Table 3. Mechanical properties of cylinder materials after prolonged contact with high-pressure hydrogen [41].

\begin{tabular}{|c|c|c|c|c|c|c|c|c|c|c|c|c|}
\hline \multirow{2}{*}{ Steel } & \multirow{2}{*}{$N$, Years } & $\sigma_{B} \times 10^{6}$ & $\sigma_{T} \times 10^{6}$ & $\delta_{5}$ & $\psi$ & $a_{1}^{293}$ & $a_{1}^{223}$ & \multirow{2}{*}{$T, \mathrm{~K}$} & \multirow{2}{*}{$\Delta, \mathrm{K}$} & \multirow{2}{*}{$\sigma_{B}^{\mathrm{H}} / \sigma_{B}$} & \multirow{2}{*}{$a_{1} / a_{T}$} & \multirow{2}{*}{$\begin{array}{l}\text { Operating Conditions of } \\
\text { Cylinders }\end{array}$} \\
\hline & & \multicolumn{2}{|c|}{$\mathrm{Pa}$} & \multicolumn{2}{|c|}{$\%$} & \multicolumn{2}{|c|}{$\mathrm{J} / \mathrm{cm}^{2}$} & & & & & \\
\hline \multirow{3}{*}{45} & 5 & 670 & 410 & 27 & 51 & 74 & 52 & 173 & 323 & 1.2 & 1.6 & \multirow{3}{*}{$\mathrm{H}_{2} ; p=15 \times 10^{6} \mathrm{~Pa}$} \\
\hline & 27 & 670 & 450 & 25 & 52 & 66 & 61 & 173 & 323 & 1.2 & 1.7 & \\
\hline & 53 & 700 & 380 & 21 & 45 & 57 & 30 & 193 & 303 & 1.2 & 5.2 & \\
\hline \multicolumn{2}{|c|}{$\begin{array}{l}\text { GOST 949-73 [44] for } \\
\text { carbon steel cylinder }\end{array}$} & $\geq 638$ & $\geq 373$ & $\geq 15$ & - & $\geq 30$ & - & $213 \div 373$ & $283-323$ & 1.4 & $1.7-5.2$ & $\begin{array}{c}\text { Compressed air; } \\
p=40 \times 10^{6} \mathrm{~Pa} ; 25 \text { years }\end{array}$ \\
\hline \multirow{3}{*}{$38 \mathrm{KhA}$} & 5 & 1020 & 840 & 14 & 58 & 72 & 52 & 178 & 278 & 1.3 & 2.9 & \multirow{3}{*}{$\mathrm{H}_{2} ; p=20 \times 10^{6} \mathrm{~Pa}$} \\
\hline & 8 & 1000 & 840 & 15 & 59 & 114 & 81 & 173 & 323 & 1.2 & 1.5 & \\
\hline & 15 & 1000 & 800 & 15 & 61 & 75 & 52 & 178 & 318 & 1.4 & 2.2 & \\
\hline \multicolumn{2}{|c|}{$\begin{array}{l}\text { GOST 9731-79 [45] for } \\
\text { alloy steel cylinder }\end{array}$} & $\geq 883$ & $\geq 687$ & $\geq 13$ & - & $\geq 61$ & $\geq 30$ & 193 & 303 & 1.2 & 2.1 & $\begin{array}{c}\text { Compressed air; } \\
p=40 \times 10^{6} \mathrm{~Pa} ; 20 \text { years }\end{array}$ \\
\hline \multirow{3}{*}{ 35KhN3MFA } & 3 & 1180 & 1090 & 16 & 60 & 112 & 93 & 173 & 323 & 1.2 & 1.4 & \multirow{3}{*}{$\begin{array}{c}\mathrm{H}_{2} ; \\
p=32 \times 10^{6} \mathrm{~Pa}\end{array}$} \\
\hline & 5 & 1150 & 1050 & 15 & 61 & 105 & 94 & 173 & 323 & 1.2 & 1.4 & \\
\hline & 8 & 1180 & 1100 & 16 & 60 & 96 & 86 & 193 & 303 & 1.3 & 1.2 & \\
\hline \multicolumn{2}{|c|}{$\begin{array}{l}\text { TU 14-3-883-79 [46] for an } \\
\text { alloy steel cylinder for } \\
\text { storing compressed air }\end{array}$} & $\geq 1150$ & $\geq 1000$ & $\geq 11$ & - & $\geq 70$ & - & $183 \div 173$ & $313-323$ & - & 1.5 & $\begin{array}{c}\text { Compressed air; } \\
p=40 \times 10^{6} \mathrm{~Pa} ; 10 \text { years }\end{array}$ \\
\hline
\end{tabular}

Designations: $\sigma_{B}$ —conditional ultimate strength; $\sigma_{T}$ 一yield point; $\delta_{5}$-relative elongation after rupture; $\psi$-relative narrowing; $a_{1}^{293}-$ impact strength at $293 \mathrm{~K} ; a_{1}^{223}$-impact strength at $223 \mathrm{~K} ; T$ is the critical temperature of brittleness; $\Delta$-viscosity reserve; become; $\sigma_{B}^{\mathrm{H}} / \sigma_{B}$-sensitivity of steel to notch under static loads; $a_{1} / a_{T}$-sensitivity of steel to notch under dynamic loads.

From a comparison of the mechanical characteristics of materials after contact with hydrogen from Table 3 with the characteristics required by regulatory documents, the authors of [41] conclude that the recorded hydrogen content in the material of the cylinders, namely

- $\quad$ up to $0.9 \times 10^{-4} \mathrm{~m}^{3} / \mathrm{kg}$ for steel 45 ,

- $1.3 \times 10^{-4} \mathrm{~m}^{3} / \mathrm{kg}$ for steel $38 \mathrm{KhA}$,

- $2.0 \times 10^{-4} \mathrm{~m}^{3} / \mathrm{kg}$ for steel $35 \mathrm{KhN} 3 \mathrm{MFA}$, 
does not significantly affect the values of $\sigma_{B}, \sigma_{T}$, and $\delta_{5}$ of the investigated steels. The specified characteristics meet the requirements and correspond to the microstructure of steels typical for the materials of cylinders of this range (Figure 2).
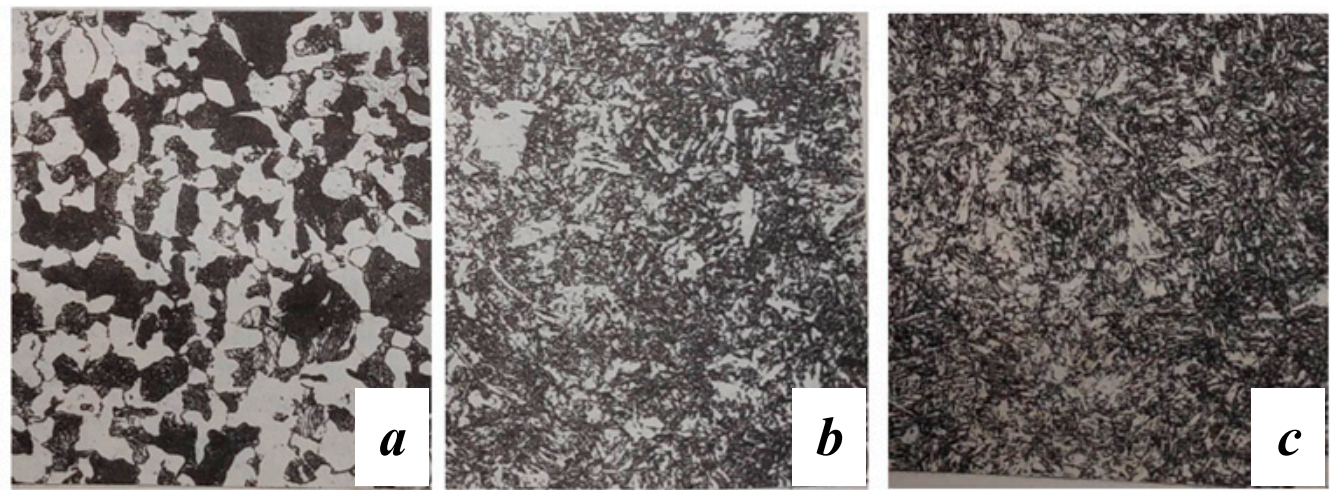

Figure 2. Microstructure of metal cylinders $(\times 500)$ after storage of compressed hydrogen: (a) steel 45; (b) $38 \mathrm{KhA}$; (c) 35KhN3MFA [41].

Table 3 shows the values of the temperature of semi-fragility $T$ of the cylinder materials after contact with hydrogen established in [41], which were used by the authors to calculate the margin of steel viscosity (Table 3), as $\Delta=|T|-\left|t_{\text {work }}\right|$, where $t_{\text {work }}$ is the minimum temperature operation of cylinders, equal to $223 \mathrm{~K}$. It also shows the values of the impact strength of the cylinder materials, established in accordance with GOST 9454-78 [47] at $293 \mathrm{~K}\left(a_{1}^{+293}\right)$ and at $223 \mathrm{~K}\left(a_{1}^{223}\right)$, as well as data on the sensitivity of steels to notching at static $\left(\sigma_{B}^{\mathrm{H}} / \sigma_{B}\right)$ and dynamic $\left(a_{1} / a_{T}\right)$ loads, where $\sigma_{B}^{\mathrm{H}}$ is the conditional ultimate strength of a cylindrical specimen with a notch radius of $0.1 \times 10^{-3} \mathrm{~m}, a_{1}, a_{T}$ is the impact strength established on specimens of type $U$ and type $T$, respectively. For comparison, in Table 3 , the same characteristics are given for the material of cylinders that have been operating under compressed air pressure for a long time (from 10 to 25 years). From the analysis of the specified data in the table, the authors of [41] conclude that there is no adverse effect of absorbed hydrogen on the operational reliability of the cylinder material.

At the same time, they note that when stretching samples of alloy steels at a very low rate (200 times less than regulated by the standard (according to GOST 1497-73 [43]), the negative effect of absorbed hydrogen still manifests itself, but only on the characteristics that are the most sensitive [26] to hydrogen embrittlement (Table 4), namely, at the true breaking stress $S_{k}$ and relative constriction $\psi$ of steels, which decrease after the samples are hydrogenated. The cracks are typical for exposure to hydrogen (Figure 3).

Table 4. Values of true breaking stress $S_{k}$ and relative constriction $\psi$ of materials used in hydrogen cylinders, established at different rates of deformation of samples [41].

\begin{tabular}{cccccc}
\hline \multirow{2}{*}{ Cylinder Material } & \multirow{2}{*}{, Years } & $S_{\boldsymbol{k}}, \mathbf{M P a}$ & $\boldsymbol{c}, \%$ & \multicolumn{2}{c}{$\Delta S_{\boldsymbol{k}}$} \\
\cline { 5 - 7 } & & & & \multicolumn{2}{c}{$\boldsymbol{\%}$} \\
\hline Steel 38KhA & 15 & $\frac{1670-1870}{1310-1990}$ & $\frac{54-63}{41-64}$ & 8.5 & 5.0 \\
\hline Steel 35KhN3MFA & 8 & $\frac{1940-2150}{1450-1990}$ & $\frac{58-61}{43-60}$ & 12.4 & 6.7 \\
\hline
\end{tabular}

Notes: 1. The numerator shows the minimum and maximum values of the properties of the samples after stretching at a speed of $0.33 \times 10^{-4} \mathrm{~m} / \mathrm{s}$, in the denominator-a speed of $0.17 \times 10^{-6} \mathrm{~m} / \mathrm{s}$. 2 . The values of properties are given according to the results of testing 10 samples. 3. $\Delta S_{k}, \Delta \psi-$ decrease in the arithmetic mean values of the parameters. 


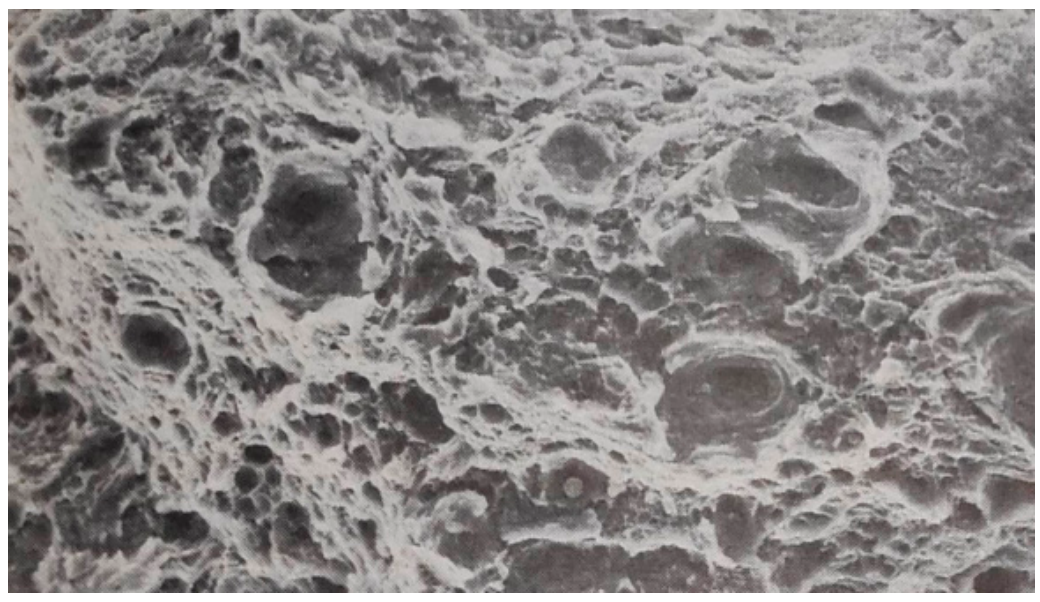

Figure 3. Fracture of the metal of the cylinders (steel 35 KhN3MFA), $\times 2000$ [41].

Thus, the results of studies [41,42] indicate that in the course of long-term operation of hydrogen cylinders, the metal of their walls becomes hydrogenated. The degree of hydrogenation depends on the chemical composition of the steel, the level of its strength, and the working pressure of hydrogen [48]. It is not possible to draw a conclusion about which of these factors is decisive from the results [41,42]. At the same time, operation of hydrogen cylinders made of carbon steel $\left(\sigma_{B}=650 \times 10^{6} \mathrm{~Pa}\right)$ for 53 years at a hydrogen saturation level of $\sim 0.004 \mathrm{~m}^{3} / 100 \mathrm{~kg}$ and for 15 years of alloy steel cylinders $\left(\sigma_{B}=900 \times 10^{6}-1150 \times 10^{6} \mathrm{~Pa}\right)$ at a hydrogen saturation level of $\sim 0.006 \mathrm{~m}^{3} / 100 \mathrm{~kg}$ does not lead to irreversible processes that deteriorate the mechanical and operational properties of the cylinder materials.

Employees of Gazprom VNIIGAZ and VNG Gasspeicher GmbH came to similar conclusions in [49], which presents the results of a study of the structure and mechanical properties of some grades of low-carbon structural steel tubing (tubing) grades D, N80, $\mathrm{J} 55$, and $13 \mathrm{Cr}$ after exposure to for $720 \mathrm{~h}$ in a moisture-saturated methane-hydrogen gas mixture with various hydrogen concentrations at a temperature of $313 \mathrm{~K}$ and a pressure of $10 \times 10^{6} \mathrm{~Pa}$. Tensile experiments on the samples were carried out on a tensile testing machine in accordance with DIN EN ISO 6892 [50]. Charpy impact tests were carried out at room temperature in a pendulum tester in accordance with the requirements of DIN EN ISO 148 [51]. The Vickers hardness test was carried out on a hardness tester with an indenter test load of $98 \mathrm{~N}$ (HV10) in accordance with the requirements of DIN EN ISO 6507-2 [52]. A change in the structure and composition was carried out using an electron microscope and a mass spectrometer.

In the course of the study, it was revealed that $720 \mathrm{~h}$ contact of the samples with the specified gas medium with a hydrogen concentration of up to $80 \%$ does not affect the main mechanical properties of the steels under study (Table 5), as well as their microstructure and chemical composition.

In their work [26], Moroz L.S. and B.B. Chechulin indicate that at low contents $\left(5 \times 10^{-5}-8 \times 10^{-5} \mathrm{~m}^{3} / \mathrm{kg}\right)$, hydrogen at normal temperature has practically no effect on the resistance of steel to plastic deformation (i.e., on the yield point of the material), but sharply decreases relative deformation before failure $\delta$ and true breaking stress $S_{k}$.

Figure 4 from this work shows the deformation curve (dependence of the true stress on the true relative deformation $\varepsilon$ ) of chromium-molybdenum steel after improvement. The end points of deformation are plotted on the curve, corresponding to the values of the true breaking stress $S_{k}$ of the samples, pre-saturated with hydrogen up to $5 \times 10^{-5} \mathrm{~m}^{3} / \mathrm{kg}$ (saturation temperature $873 \mathrm{~K}$, increased hydrogen pressure, exposure to hydrogen for $2 \mathrm{~h}$ ), and kept at room temperature for different times (from $1 \mathrm{~h}$ to 21 days). 
Table 5. Mechanical properties of the studied steel grades before and after exposure to an aggressive environment with different hydrogen concentrations [49].

\begin{tabular}{|c|c|c|c|c|}
\hline $\begin{array}{c}\text { Indicator of } \\
\text { Mechanical } \\
\text { Properties of Steel }\end{array}$ & Steel Grade & $\begin{array}{c}\text { Before Exposure of } \\
\text { Hydrogen-Containing } \\
\text { Gas }\end{array}$ & $\begin{array}{l}\text { After Exposure of the } \\
\text { Moisture-Saturated Mixture } \\
\text { of Gases }\left(80 \% \mathrm{H}_{2} ; 20 \% \mathrm{CH}_{4}\right)\end{array}$ & $\begin{array}{l}\text { After Exposure of the } \\
\text { Moisture-Saturated Mixture } \\
\text { of Gases }\left(20 \% \mathrm{H}_{2} ; 80 \% \mathrm{CH}_{4}\right)\end{array}$ \\
\hline \multirow{4}{*}{$\begin{array}{l}\text { Tensile strength, } \\
10^{6} \mathrm{~Pa}\end{array}$} & $\mathrm{D}$ & 742.3 & 720.7 & 739.7 \\
\hline & N80 & 648.7 & 644.3 & 653 \\
\hline & $\mathrm{J} 55$ & 736.7 & 736 & 743.7 \\
\hline & $13 \mathrm{Cr}$ & 768.3 & 758.7 & 779.3 \\
\hline \multirow{4}{*}{$\begin{array}{l}\text { Impact strength, } \\
\qquad 10^{-4} \mathrm{~J} / \mathrm{m}^{2}\end{array}$} & $\mathrm{D}$ & 45 & 46 & 46 \\
\hline & N80 & 131 & 129 & 129 \\
\hline & $\mathrm{J} 55$ & 134 & 129 & 129 \\
\hline & $13 \mathrm{Cr}$ & 240.3 & 211 & 221 \\
\hline \multirow{4}{*}{$\begin{array}{l}\text { Vickers hardness } \\
\text { value, } \mathrm{HV}_{10}\end{array}$} & $\mathrm{D}$ & 229 & 233 & 231 \\
\hline & N80 & 225 & 225 & 225 \\
\hline & $\mathrm{J} 55$ & 216 & 215 & 215 \\
\hline & $13 \mathrm{Cr}$ & 247 & 247 & 246 \\
\hline
\end{tabular}

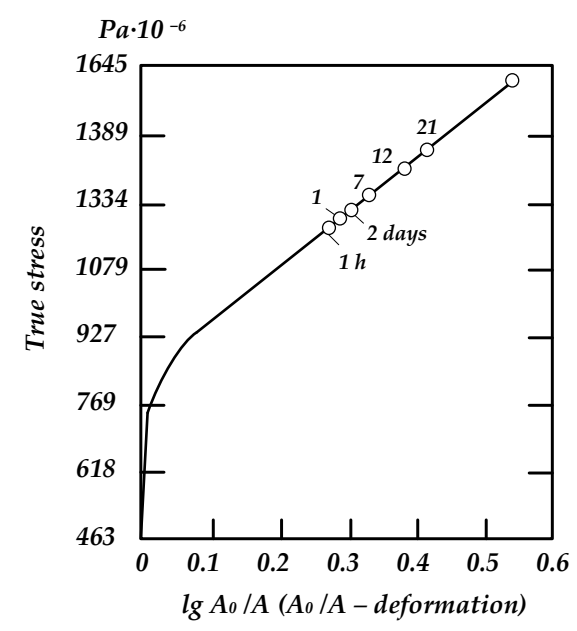

Figure 4. Curves of deformation of steel samples $(0.3 \% \mathrm{C}, 3 \% \mathrm{Cr}, 0.4 \% \mathrm{Mo})$, held after hydrogenation for various times before testing [26]. The numbers on the curves are the duration of the preliminary exposure of the samples to atmospheric conditions at $293 \mathrm{~K}$.

As can be seen from Figure 4, as the duration of holding the samples at room temperature increases and, as can be assumed, the spontaneous removal of absorbed hydrogen from them, the ductility (elongation $\delta$ ) and strength (true breaking stress $S_{k}$ ) of steel increase and approach the level of characteristics demonstrated by steel samples before hydrogenation $\left(\delta \sim 0.55 ; S_{k} \sim 1600 \times 10^{6} \mathrm{~Pa}\right)$. In this case, all points fit into the deformation curve of steel not saturated with hydrogen. This, in the opinion of the authors of [26], confirms the conclusion about the absence of the effect of small amounts of hydrogen on the resistance of steel to plastic deformation.

From the data in Figure 4, another conclusion can be drawn that after artificial saturation of steel with hydrogen, it is able to spontaneously release from the metal until its equilibrium concentration is reached there, corresponding to the temperature and partial pressure of hydrogen in the environment.

Figure 5 shows the dependence [26] of the ultimate plasticity (relative narrowing) of $34 \mathrm{KhM}$ steels $\left(\sigma_{B}=637 \times 106 \mathrm{~Pa}\right.$; C $0.3-0.4 \%$; Mn 0.4-0.7\%; Cr 0.9-1.3\%), 34KhN2M $\left(\sigma_{B}=561 \times 106 \mathrm{~Pa} ; \mathrm{C} 0.3-0.4 \% ; \mathrm{Mn} 0.5-0.8 \% ; \mathrm{Cr} 1.3-1.7 \% ; \mathrm{Ni} 1.7-2.7 \%\right)$, and 34KhN3M $\left(\sigma_{B}=766 \times 106 \mathrm{~Pa} ; \mathrm{C} 0.3-0.4 \% ; \mathrm{Mn} 0.5-0.8 \% ; \mathrm{Cr} 0.7-1.1 \%\right.$; Ni 2.75-3.25\%) of the content in the samples of hydrogen introduced into the metal by electrolytic saturation. Based on the form of the dependences of the figure, the authors of [26] come to the conclusion that 
already at a hydrogen content of $6 \times 10^{-5} \mathrm{~m}^{3} / \mathrm{kg}$, the ductility of steel $34 \mathrm{KhM}(1)$ and $34 \mathrm{KhN} 2 \mathrm{M}$ (2) decreases five times compared to the initial level. In this case, the decrease in plasticity upon saturation with hydrogen occurs almost entirely due to the concentrated part of the deformation while maintaining the uniform deformation.

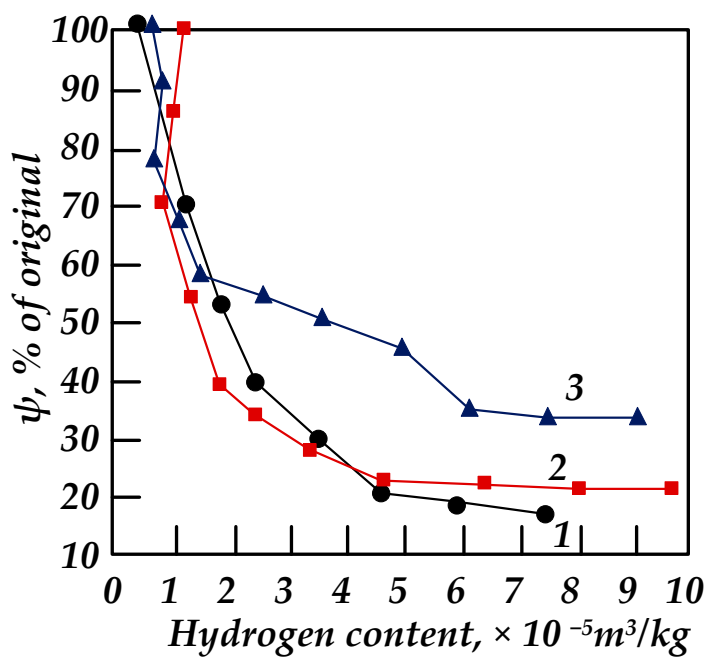

Figure 5. Influence of hydrogen contained in steel on the relative narrowing of steels $34 \mathrm{KhM}$ (1), $34 \mathrm{KhN} 2 \mathrm{M}(2)$, and 34KhN3M (3) [26].

In experiments [26], the results of which are illustrated in Figure 6a,b, cylindrical steel samples (C $0.36 \%$, Mn $1.54 \%$, Si $1.50 \%$, Ni $1.77 \%$, Mo $0.40 \%$, and V $0.22 \%$ ) were thermally treated to give them different strengths ( $\sigma_{B}$ value), after which they were subjected to cathodic hydrogenation in $4 \% \mathrm{H}_{2} \mathrm{SO}_{4}$ to different concentrations of absorbed hydrogen. It can be seen (Figure 6) that with an increase in the concentration of absorbed hydrogen in steel, its strength properties (ultimate strength $\sigma_{B}$ ) and plastic (relative narrowing $\psi$ ) decrease. Moreover, the specified reduction is manifested the more intensively, the stronger the steel.
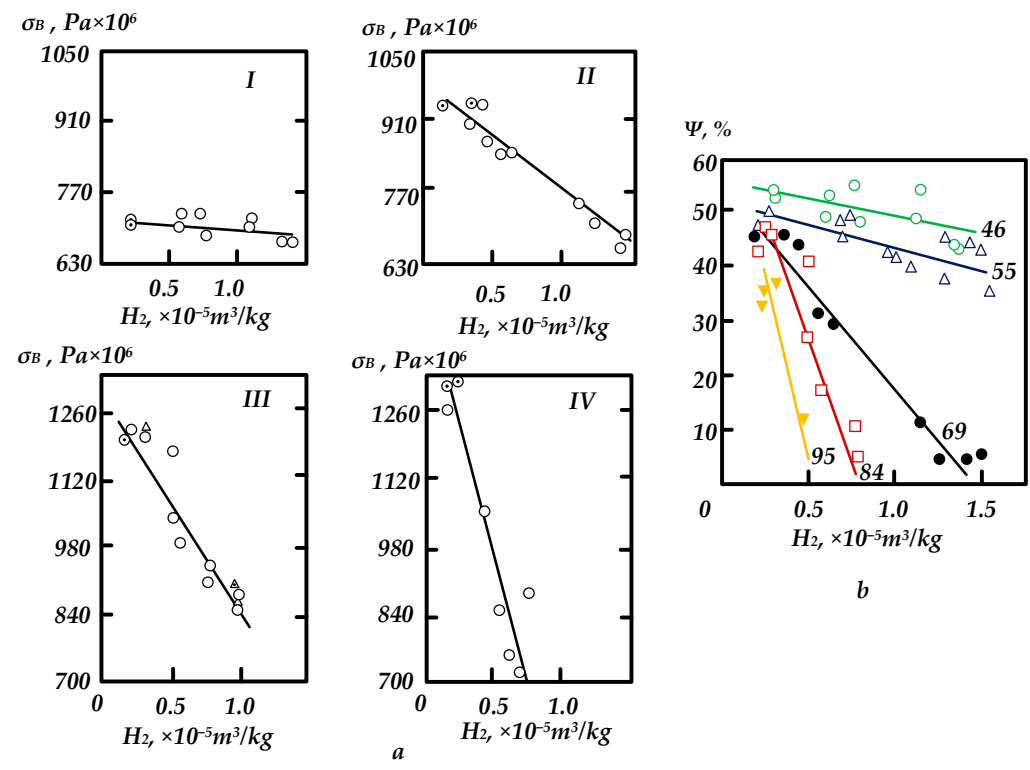

Figure 6. Dependence of the conditional ultimate strength (a) and relative contraction (b) of steel of different initial strength on the hydrogen content in it: I-460 × $10^{6} \mathrm{~Pa}$; II $-690 \times 10^{6} \mathrm{~Pa}$; III$840 \times 10^{6} \mathrm{~Pa} ; \mathrm{IV}-950 \times 10^{6} \mathrm{~Pa}$ [26]. 
In the same work [26], the authors note the peculiarity of the manifestation of hydrogen brittleness of steel (a decrease in its plastic characteristics) depending on the rate of deformation. The greatest brittleness in samples saturated with hydrogen is observed at low deformation rates; with their increase, the brittleness decreases and at sufficiently high rates it may not manifest itself at all. This pattern is confirmed by the results (Figure 7) obtained on electrolytically hydrogenated Armco-iron samples subjected to tension at different strain rates. (Accelerated stretching in [26] was performed using a hydraulic press at a speed of copra with the help of a special device with a speed of $\sim 4 \mathrm{~m} / \mathrm{s}$.)

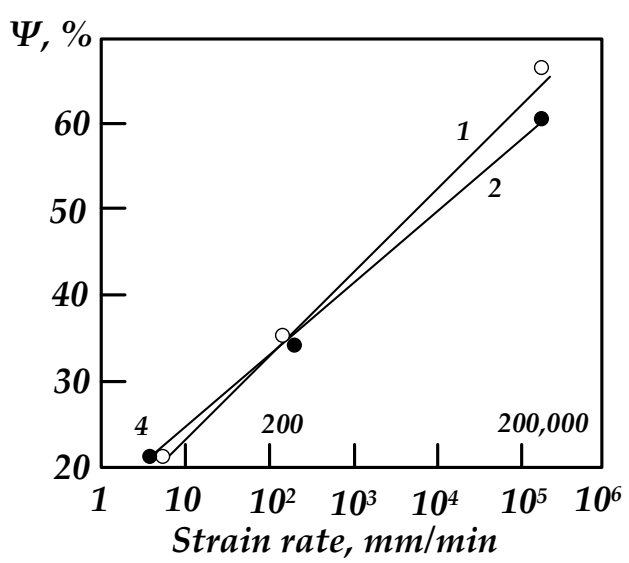

Figure 7. Influence of the strain rate on the relative narrowing of hydrogen-saturated Armco-iron samples: at 2 h electrolytic saturation (1); at high temperature (2) [26].

Before saturation with hydrogen, the relative transverse contraction at low and high rates of extension was the same and amounted to $\sim 65 \%$. After electrolytic hydrogenation (curve 1 in Figure 7) for specimens stretched at low speed, it decreased to $20 \%$. With an increase in the deformation rate, the plasticity of the hydrogenated specimens increases sharply and, during pounding tests $(\mathrm{v} \sim 4 \mathrm{~m} / \mathrm{s})$, reaches the level demonstrated by the non-hydrogenated specimens, i.e., $65 \%$.

The authors of [26] note that during electrolytic saturation, hydrogen is very unevenly distributed over the cross section of the sample. To find out whether this irregularity affects the dependence of the intensity of the manifestation of hydrogen embrittlement on the rate of deformation, they conducted an experiment with samples subjected to high-temperature saturation in a hydrogen atmosphere ( $1 \mathrm{~h}$ at $1473 \mathrm{~K})$. After saturation with hydrogen, the samples were quenched in water and tested for tension at different rates (curve 2 in Figure 7).

Good coincidence of the curves shown in the figure, one of which was obtained when testing samples electrolytically saturated with hydrogen (i.e., having an uneven distribution of hydrogen over the cross section), and the other, for samples subjected to high-temperature saturation (i.e., with a quasi-uniform distribution of hydrogen), shows, according to the authors, that the nature of the rate dependence of plasticity is the same and does not depend on the method of saturation with hydrogen. At high-temperature saturation, destruction occurs in the same way as during electrolytic saturation. (It should be noted that, according to [53], the electrochemical method of hydrogenation can sometimes lead to a high hydrogen content at the surface, which can cause surface cracking or the formation of bubbles [54], i.e., the question of the equivalence of the methods of saturation with hydrogen of the samples under study requires additional research.)

In the same place (in [26]), the effect of the deformation rate on the fracture work of steels in a brittle state (after treatment for hardness $>60 \mathrm{HRC}$ ) is studied. Smooth cylindrical specimens $0.01 \mathrm{~m}$ in diameter were subjected to electrolytic hydrogenation and tested for transverse bending by a force in the center of the sample. The results are shown in Table 6. 
Table 6. Change in the work of destruction $(\mathrm{J})$ of steel smooth samples under the influence of "internal" hydrogen at static and dynamic bending [26].

\begin{tabular}{|c|c|c|c|c|c|c|}
\hline \multirow{2}{*}{$\begin{array}{l}\text { Steel Grade and Chemical } \\
\text { Composition, } \%\end{array}$} & \multicolumn{3}{|c|}{$\begin{array}{l}\text { Static Loading } \\
\left(0.33 \times 10^{-5} \mathrm{~m} / \mathrm{s}\right)\end{array}$} & \multicolumn{3}{|c|}{ Dynamic Loading } \\
\hline & $\begin{array}{c}\text { Not } \\
\text { Hydrogenated }\end{array}$ & Hydrogenated & $\begin{array}{l}\text { Reduction of } \\
\text { Work, \% }\end{array}$ & $\begin{array}{c}\text { Not } \\
\text { Hydrogenated }\end{array}$ & Hydrogenated & $\begin{array}{l}\text { Reduction of } \\
\text { Work, \% }\end{array}$ \\
\hline $\begin{array}{c}\text { Kh4V3M3F2 } \\
\text { (C 0.85; Cr 4.5; Mo 3; V 2.5; W 3.2) }\end{array}$ & 38,95 & 12,07 & 69 & 42,2 & 38,2 & 10 \\
\hline $\begin{array}{c}\text { Kh12M } \\
\text { (C 1.65; Cr 12.5; Mo 0.6) }\end{array}$ & 30,4 & 4.9 & 84 & 41,2 & 29,4 & 29 \\
\hline $\begin{array}{l}\mathrm{U} 10(\mathrm{C} 1) \\
(\text { melting } 1)\end{array}$ & 28,5 & 9.4 & 67 & 23,7 & 15,7 & 38 \\
\hline $\begin{array}{c}\text { U10 (C 1) } \\
\text { (melting 2) }\end{array}$ & 37,6 & 1.76 & 95 & 40,6 & 30,4 & 24 \\
\hline
\end{tabular}

Test temperature $293 \mathrm{~K}$. Each point is the average of five values.

It can be seen (Table 6) that, both under static and dynamic loading, the hydrogenation of all analyzed steels in a brittle state leads to a decrease in their fracture work. This is especially clearly manifested in the case of static loading, in which the work of destruction, for example, of U8 steel has decreased as a result of hydrogenation by almost two times.

As follows from Table 7 [26], the presence of hydrogen in steels reduces their impact strength. In this case, the degree of decrease in the impact toughness is influenced not only by the hydrogen content, but also by the nature of the alloying of the steel [55].

Table 7. Values of steel impact strength before and after hydrogenation [26].

\begin{tabular}{|c|c|c|c|c|}
\hline $\begin{array}{c}\text { Steel Grade and Chemical } \\
\text { Composition, } \%\end{array}$ & $\begin{array}{c}\text { Original } \\
\mathrm{J} / \mathrm{m}^{2} \times 10^{-3}\end{array}$ & $\begin{array}{l}\text { After Hydrogenation } \\
\qquad \mathrm{J} / \mathrm{m}^{2} \times 10^{-3}\end{array}$ & $\begin{array}{l}\text { Decrease as a Result } \\
\text { of Hydrogenation, } \%\end{array}$ & $\begin{array}{c}\text { Hydrogen Content in } \\
\text { a Hydrogenated } \\
\text { Sample, } \mathrm{cm}^{3} / 100 \mathrm{~g}\end{array}$ \\
\hline 35 (C 0.35) & 1470 & 1290 & 12 & 3.8 \\
\hline 35Kh3 (C 0.35; Cr 3) & 1130 & 540 & 52 & 7.3 \\
\hline 35Kh3M (C 0.35; Cr 3; Mo 1) & 1730 & 1560 & 10 & 8.4 \\
\hline 35KhB2M (C 0.35; Cr 1; V 2; Mo 1) & 1070 & 850 & 20 & 5.8 \\
\hline
\end{tabular}

The authors of [56] present data on hydrogen embrittlement of a material recommended for use in hydrogen sulfide environments-low-carbon steel $20 \mathrm{YuCh}$ (C $0.16-0.22 \%$; Al 0.03-0.1\%; Ce 1.5\%) doped with cerium. A series of samples was made from this material, some of which were subjected to electrolytic hydrogenation. Immediately after hydrogenation, the samples were tensile tested in accordance with GOST 1497-84 [43] at room temperature. The test results of hydrogenated samples were compared with the data obtained by stretching similar samples in the initial state (Table 8).

Table 8. Mechanical properties of 20YuCh steel samples before and after hydrogenation [56].

\begin{tabular}{|c|c|c|c|c|c|c|c|c|c|}
\hline \multirow{2}{*}{ Material } & \multicolumn{4}{|c|}{ Mechanical Characteristics } & \multirow{2}{*}{ HV } & \multirow{2}{*}{$\begin{array}{c}\text { Viscosity/ } \\
\text { Brittleness, \% }\end{array}$} & \multirow{2}{*}{$\Delta \Psi, \%$} & \multirow{2}{*}{$\Delta \delta, \%$} & \multirow{2}{*}{$\Delta \sigma, \%$} \\
\hline & $\sigma_{T}, \times 10^{6} \mathrm{~Pa}$ & $\sigma_{B}, \times 10^{6} \mathrm{~Pa}$ & $\delta_{5}, \%$ & $\Psi, \%$ & & & & & \\
\hline $\begin{array}{c}\text { Before } \\
\text { hydrogenation }\end{array}$ & 27.7 & 63.7 & 37 & 70 & 201 & $100 / 0$ & \multirow[t]{2}{*}{41} & \multirow[t]{2}{*}{30} & \multirow[t]{2}{*}{4.2} \\
\hline $\begin{array}{c}\text { After } \\
\text { hydrogenation }\end{array}$ & 35.1 & 5.1 & 26 & 41.5 & 174 & $25 / 75$ & & & \\
\hline
\end{tabular}

As shown by the test results (Table 8), as a result of hydrogenation, the plastic characteristics of the metal of the studied steel samples change most significantly. For example, the relative elongation $\delta_{5}$ decreased by $30 \%$, and the relative narrowing by $41 \%$; in the microstructure of the fracture of the samples, up to $75 \%$ of a brittle component appeared. 
Thus, despite the fact that steel $20 \mathrm{YuCh}$ is positioned as corrosion-resistant, it also exhibits a tendency to hydrogen embrittlement.

When considering the concept of hydrogen embrittlement [57-59], due to the saturation of steel with hydrogen, the following manifestations are distinguished [60]:

- $\quad$ the presence of bubbles or voids filled with hydrogen under high pressure [61];

- reduction of surface energy [62];

- $\quad$ ejection of dislocations from the surface or near-surface region [63];

- decrease in cohesive strength [64];

- local plasticity [65];

- creation of vacancies and deformations $[66,67]$;

- transition from ductile to brittle fracture $[68,69]$;

- $\quad$ formation and splitting of hydrides [70];

- phase transformations caused by hydrogen and deformation [71];

- chemical interactions of hydrogen with alloy elements [72].

\section{Influence of "External" Hydrogen on the Mechanical Properties of Steels}

As shown by a review of literature data, information on the mechanical properties of pipeline steels demonstrated when testing materials in a hydrogen atmosphere, i.e., in "external" hydrogen, is very limited. In this regard, of particular interest are the results of a study [34] carried out on low-carbon microalloyed pipeline steel of strength class X80 (Table 9), used due to its good weldability, high strength, and good ductility as a material of underground gas pipelines.

Table 9. Chemical composition of steel of strength class X80 (wt.\%) [34].

\begin{tabular}{ccccccccc}
\hline Element & $\mathbf{C}$ & $\mathbf{M n}$ & $\mathbf{S i}$ & $\mathbf{N i}$ & $\mathbf{M o}$ & $\mathbf{C r}$ & $\mathbf{N b}+\mathbf{V}+\mathbf{T i}$ & $\mathbf{F e}$ \\
\hline Content & 0.061 & 1.81 & 0.28 & 0.03 & 0.22 & 0.03 & 0.147 & Remaining \\
\hline
\end{tabular}

The influence of "internal" and "external" hydrogen on the mechanical properties of steel was assessed by testing the samples for tensile to rupture, carried out with 2 strain rates: $2 \times 10^{-5} \mathrm{~s}^{-1}$ (called the "slow" strain rate) and $2 \times 10^{-4} \mathrm{~s}^{-1}$ ("high" deformation rate). Some of the samples were subjected to preliminary hydrogenation by the method of electrochemical charging, in which the samples were charged in an aqueous solution of sulfuric acid and thiourea at $298 \mathrm{~K}$ (a more obvious phenomenon of hydrogen embrittlement, while the hydrogen content in the samples after electrochemical charging is easier to measure). The original and hydrogenated samples were tested both in air and in an aqueous solution of sulfuric acid and thiourea, where they were simultaneously adsorbed ("external") hydrogen. To prevent the spontaneous release of hydrogen from the samples, a cadmium coating was applied to some of the samples after hydrogenation. Sample test conditions are shown below:

No. 1-without preliminary hydrogenation when tested in air at a slow rate of deformation;

No. 2-pre-hydrogenated when tested in air at a slow rate of deformation;

No. 3-pre-hydrogenated when tested in air at a high rate of deformation;

No. 4-without preliminary hydrogenation during testing in the environment of "external" hydrogen at a slow rate of deformation;

No. 5-pre-hydrogenated when tested in an environment of "external" hydrogen at a slow rate of deformation.

The test results are presented in Table 10 and Figure 8. 
Table 10. Mechanical parameters of pipeline steel of strength class X80 when testing samples of initial $(1,3,4)$ and hydrogenated $(2,5)$ in air $(1,2)$ and in the presence of external hydrogen $(3,4,5)[61]$.

\begin{tabular}{cccc}
\hline Sample Number & Yield Point, $\sigma_{\boldsymbol{s}}, \times \mathbf{1 0}^{\mathbf{6}} \mathbf{P a}$ & Elongation $\delta, \mathbf{o}$ & $\begin{array}{c}\text { Relative Extension } \\
\delta_{\boldsymbol{H}} / \delta_{\text {air }} \boldsymbol{\%}\end{array}$ \\
\hline 1 & 560 & 17.8 & - \\
2 & 560 & 11.5 & 64.6 \\
3 & 560 & 5.1 & 28.6 \\
4 & 560 & 3.8 & 21.3 \\
5 & 560 & 2.1 & 11.8 \\
\hline
\end{tabular}

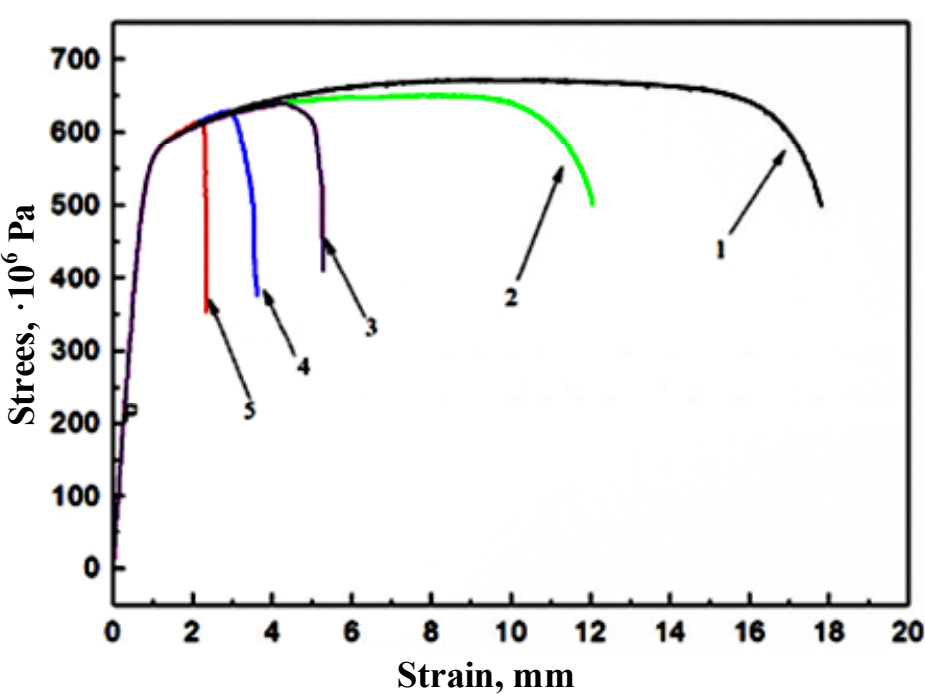

Figure 8. Tension diagram of samples of pipeline steel $\mathrm{X} 80$ in air and in the presence of external hydrogen when tested with a low strain rate $\left(2 \times 10^{-5}\right)$ [34].

As can be seen from the data in Table 10 and Figure 8, the value of the yield strength of steel, regardless of the nature of the test medium and the presence of hydrogen in the metal, remains unchanged. At the same time, relative elongation (relative deformation at the moment of fracture) and conditional ultimate strength (maximum on the deformation curve of the pattern) for specimens exposed to both "internal" (sample No. 2) and "external" (samples No. 3, No. 4) hydrogen was less than that of the original steel sample when it breaks in air. A particularly negative effect of hydrogen is manifested in the value of $\delta$ in the sample under the simultaneous influence of "internal" and "external" hydrogen, for example sample No. 5 value of $\delta$ changes from 17.8 to $2.1 \%$, i.e., decreases more than 8 times.

Analyzing the results obtained, the authors of [34] note that the ductility of the X80 pipeline steel is influenced by both the "internal" hydrogen in the volume of the metal and the "external" hydrogen, for which the authors of [34] take hydrogen "absorbed by the surface", i.e., located on the surface in an adsorbed state. In the process of hydrogenation, its atoms penetrate into the metal and become "internal" hydrogen with the achievement of dynamic equilibrium between hydrogen "absorbed by the surface" and "internal" hydrogen.

Based on the shape of the curves in Figure 8, the authors of [34] conclude that the main role in the occurrence of hydrogen embrittlement is played, namely, by the "external" hydrogen. The reason for this is that its effective concentration is higher than the concentration of "internal" hydrogen. This is explained by the fact that the limiting hydrogen content in the lattice of bcc steels is very low [39], usually only a few parts per million, while the hydrogen concentration in the adsorbed layer of atoms on the metal surface can be much higher. From the morphology of cracks, it can be seen that cracks during hydrogenation are formed on the surface, whether it is an adsorbed hydrogen medium 
or an "internal" hydrogen medium. This indicates that the motion of dislocations on the surface and in the subsurface layer plays a dominant role in the formation of cracks [27]. Hydrogen adsorbed on the surface is more easily trapped by dislocations, therefore the effect produced by hydrogen absorbed by the surface is higher than by internal hydrogen

The study of the effect of gaseous hydrogen on the mobility of dislocations in steel is the subject of the work of Ian Robertson [57]. In it, the author gives the results of experiments on observation with the help of a transmission electron microscope over the movement of dislocations of a steel foil sample under a load. The microscope was preliminarily modified so that it was possible to fill the volume between the sample and the pole piece of the objective with a gaseous hydrogen medium.

Two types of experiments were carried out. The first included the introduction of a gaseous medium while maintaining a constant load on the sample. The effect manifested itself in a change in the velocity of movement of dislocations. The second experiment included the creation of mobile dislocations, maintaining the speed of their motion at a constant level and stopping it, adding gaseous hydrogen to the volume above the sample and observing its effect on motionless dislocations.

The results of both experiments were consistent with each other and showed that the introduction of gaseous hydrogen causes an increase in the velocity of dislocation motion. Removing gas from the volume caused the effect of stopping their movement. It was found that this effect does not depend on the structure of the material and the type of dislocation, but depends on the purity of the material and on the pressure of the introduced hydrogen gas. The results of observations of the enhancement of the motion of dislocations in a hydrogen atmosphere were initially disputed, and it was suggested that this was the effect of a thin foil or a pressure drop created by the introduction of a gas medium into the pole piece of an electron microscope objective. To demonstrate that dislocation motion is achieved only in the presence of hydrogen, the experiments were repeated using either dry or water-saturated inert gases. Strengthening of the dislocation movement occurred only in the water-saturated state, which was associated with hydrogen generated from water.

The author in his work [57] raises the question of the critical level of hydrogen pressure required for the onset of intercrystalline fracture, as well as how this level can be achieved. He also concludes that further studies are needed to determine the intensity of the decrease in the cohesive strength of grain boundaries by hydrogen in systems in which the action of hydrogen, as is known, leads to brittle intercrystalline fracture [39].

In addition to the generally accepted tensile tests in the modern scientific community, indentation tests using microsamples are becoming more and more popular, as they require lower costs of the test material and a smaller sized experimental setup [53,73,74].

For example, in [53], the results of experiments on pressing a steel indenter into microsamples made of pipe steel X70 are presented. A gas mixture of methane with hydrogen of various concentrations, or pure hydrogen, was fed to the opposite side of the microsample under increased pressure. In the process of indentation, the load applied to the sample was recorded as a function of the displacement of the indenter. The setup diagram and the resulting diagrams are shown in Figures 9 and 10.

Based on the form of the obtained diagrams, the authors of [53] conclude that in the initial region of deformations corresponding to the region of elastic bending, the curves are very similar to each other, which indicates that the presence of a hydrogen-containing gas mixture, like pure hydrogen, does not have a significant effect on the mechanical properties of the sample in the area of elastic deformations. At the same time, in the later deformation regions of the curves, their clear differences are observed. The areas of plastic bending and stretching of the sample have higher load and deformation indices when tested in air compared to these indices corresponding to a mixture of methane with hydrogen. In this case, the effect of hydrogen is observed already at a concentration of $0.1 \%$. The transferred maximum loads and deformations tend to decrease with increasing hydrogen concentration and sharply decrease when its concentration reaches $3 \%$. According to the authors, the effect of the hydrogen concentration in the gas mixture on the mechanical 
characteristics is more pronounced than the effect of the pressure of the gas mixture, and the effect of prolonged exposure to hydrogen on the degree of hydrogen embrittlement is insignificant (Figure 11). The results obtained correlate with the data given in [75-77].

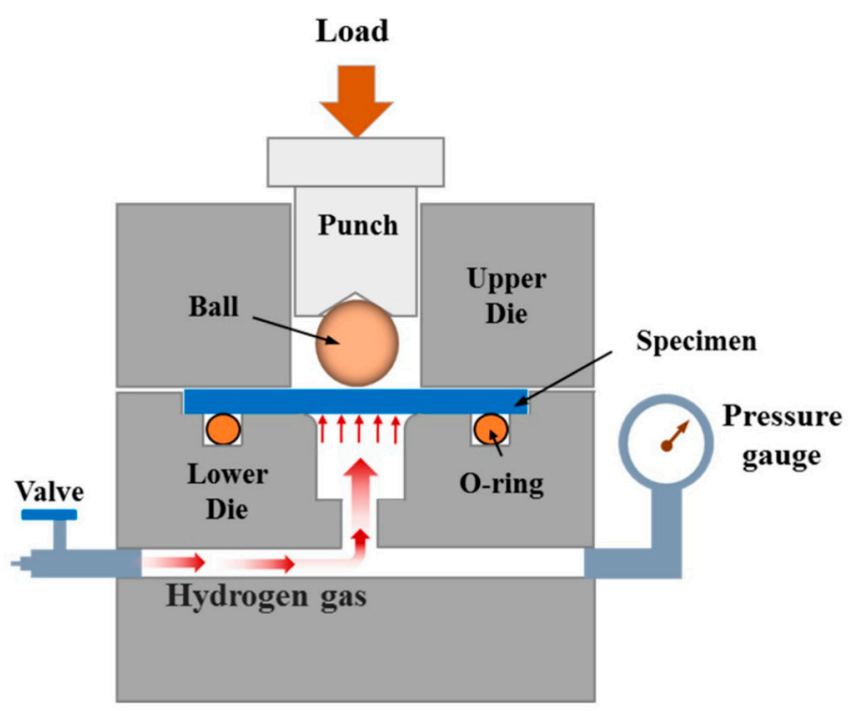

(a)

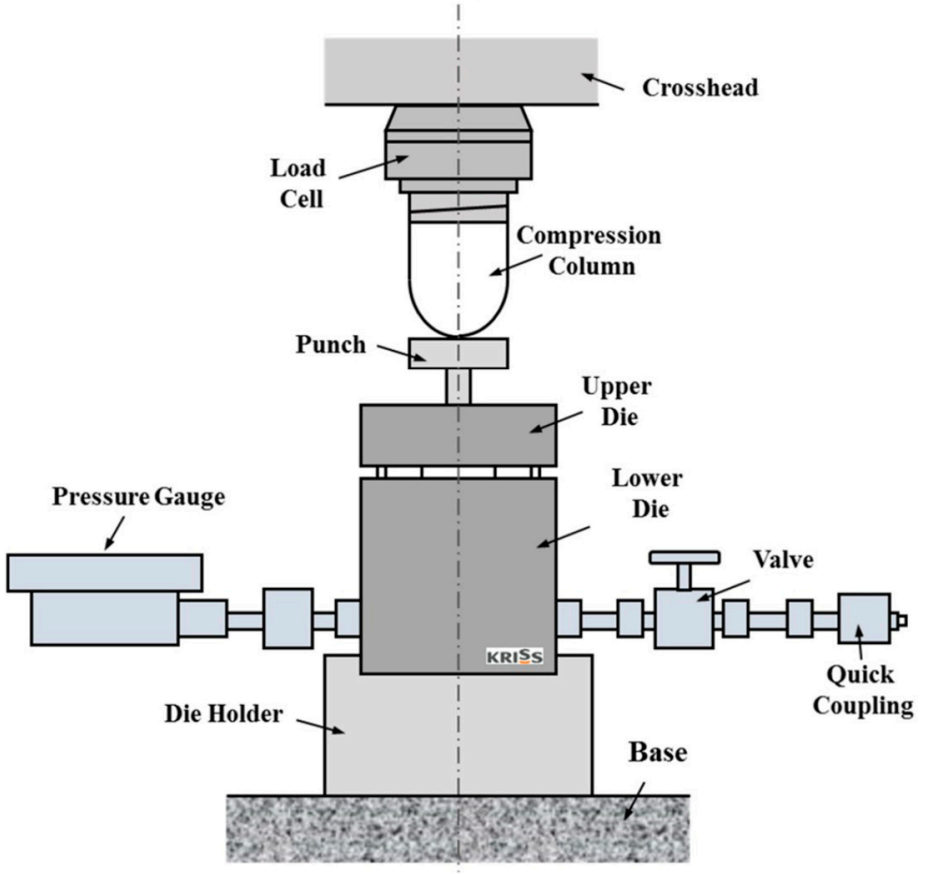

(b)

Figure 9. Schematic illustration of SP test with gaseous environments: (a) SP test jig, (b) test equipment [53].

Comparison of the results of tests [53] for indentation with the results of tests [78,79] for tensile, shows a higher level of hydrogen embrittlement when testing steels, which is explained by differences in the method of hydrogenation, since in [53], hydrogenation was performed in an atmosphere of gaseous hydrogen, and in [78,79], electrochemically charged samples were used.

In [42], during mechanical tests of steel samples 45 (C 0.42-0.5\%) and 38KhA (C $0.35-$ $0.42 \%$ ) in an atmosphere of gaseous hydrogen, the author discovers that with an increase in the pressure of the surrounding hydrogen, decrease in strength characteristics of smooth specimens and, especially, specimens with a stress concentrator. The greatest decrease 
in strength characteristics (up to $70 \%$ of the total decrease in properties) is observed in the region of low hydrogen pressure (up to $4 \times 10^{6} \mathrm{~Pa}$ ). If in steel 45 the decrease in the properties of smooth samples is up to $30 \%$, then in steel $38 \mathrm{KhA}$ it is already up to $60 \%$ of the total decrease in mechanical properties. (The absolute values of the mechanical characteristics are not given in [42].) As an indicator characterizing the structural reliability of a material in a high-pressure hydrogen environment, the author proposes to use the ratio of the ultimate strength of notched and smooth specimens, i.e., parameter $\sigma_{B}^{\mathrm{H}} / \sigma_{B}$. The values of this index of the sensitivity of steel to a notch in a hydrogen environment under a pressure of $40 \times 10^{6} \mathrm{~Pa}$ turned out to be below unity (for steel $45-0.98$, for steel $38 \mathrm{KhA}-$ 0.85), which characterizes the state of the metal, in which, according to the author [42], the presence of voltage concentrators is especially dangerous.

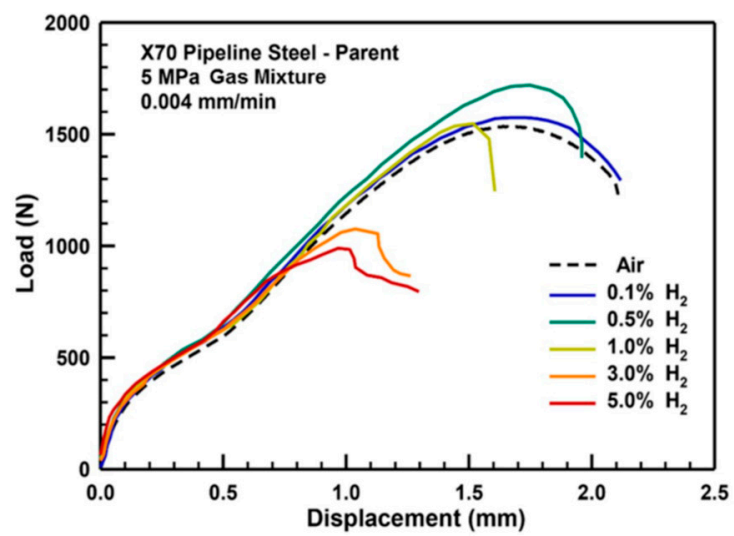

(a)

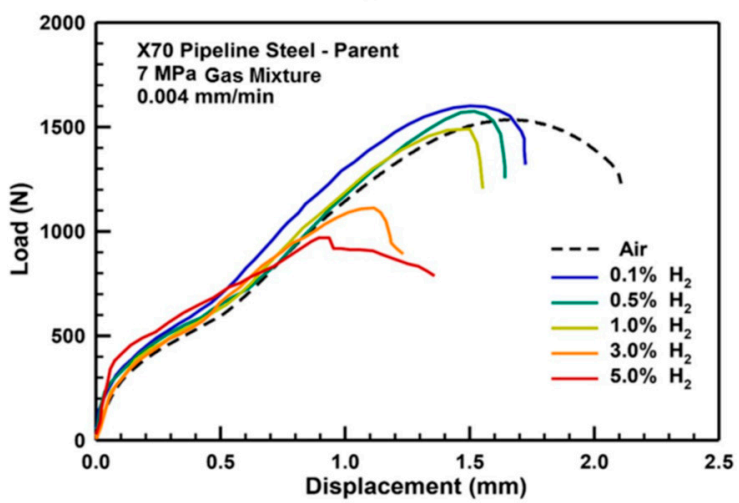

(b)

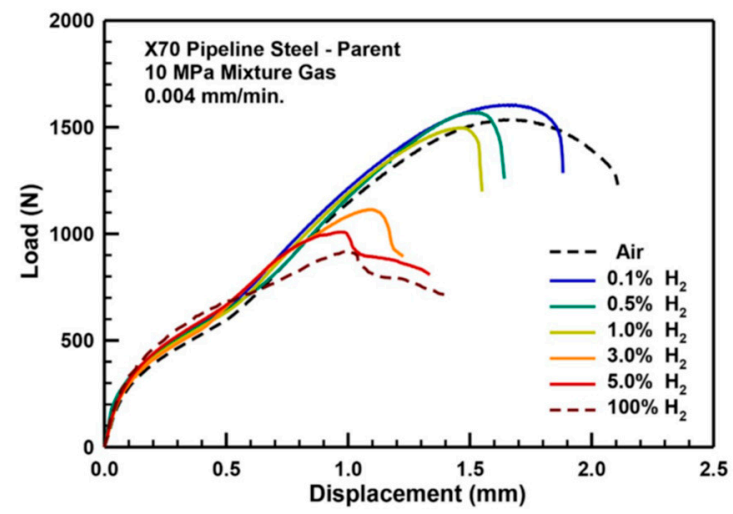

(c)

Figure 10. Load-punch displacement curves of SP test with respect to variations in the gas mixture at (a) $5 \mathrm{MPa}$, (b) $7 \mathrm{MPa}$, (c) $10 \mathrm{MPa}$ [53]. 


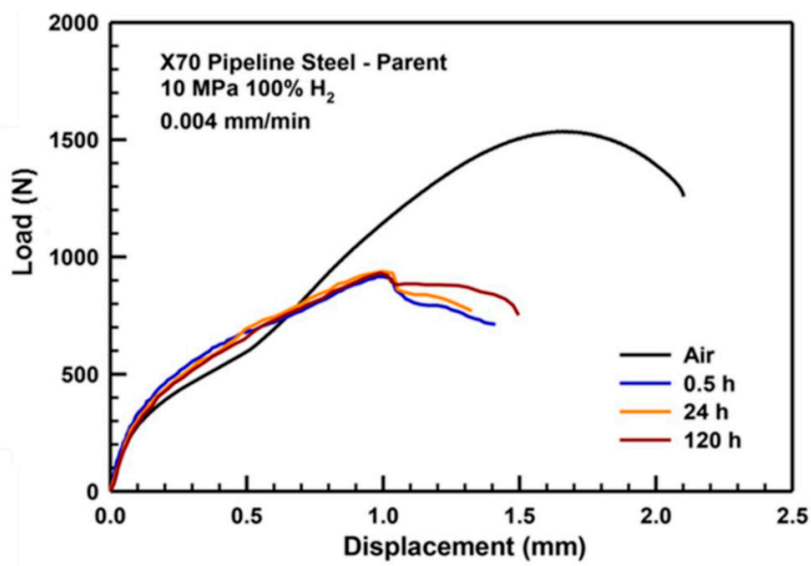

(a)

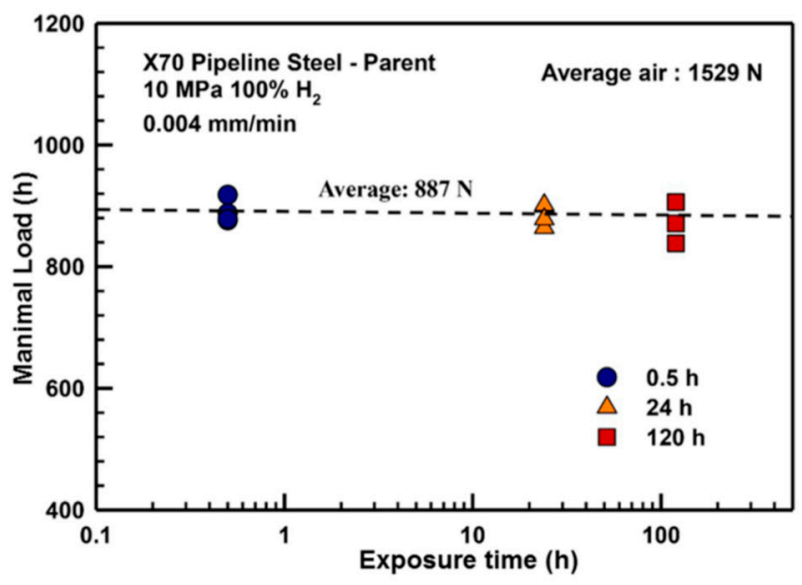

(b)

Figure 11. Influence of hydrogen exposure time on SP test results: (a) comparison of typical loadpunch displacement curves, (b) maximal load with respect to exposure time [53].

In [80], the authors investigate the effect of "external" hydrogen on the growth rate of a fatigue crack in two pipeline steels of strength classes X52 and X100. The results of tests in the atmosphere of compressed hydrogen gas are compared with the results of tests of steels in air. For this, notched specimens prepared in accordance with ASTM E647-05 [81] were pre-cycled in air to form a fatigue sharp crack at the notch tip and placed in an autoclave of a specially designed test setup, where the effect of hydrogen gas at pressures of $1.7 \times 10^{6}$; $7 \times 10^{6} ; 21 \times 10^{6}$, and $48 \times 10^{6} \mathrm{~Pa}$ for the fatigue crack growth rate. Fatigue tests were carried out using a power frame capable of generating a load of $100 \times 10^{3} \mathrm{~N}$ at a frequency of $1 \mathrm{~Hz}$ for 3-7 days and at a frequency of $0.1 \mathrm{~Hz}$ for 21 days. According to the test results, it was found that for the steels under study, the fatigue crack growth rate is one to two orders of magnitude higher in a hydrogen environment than in air. It was also observed that the lower the cycling frequency, the higher the growth rate of the fatigue crack. The effect of decreasing frequency is similar to increasing gas pressure.

\section{Materials Recommended for Use in a Hydrogen Environment}

According to GOST 949-73 [44], for storage of gaseous hydrogen with a working pressure of up to $19.6 \times 10^{6} \mathrm{~Pa}$, cylinders made of carbon and alloy steel with a volume of up to $0.05 \mathrm{~m}^{3}$, made of seamless pipes and intended for storage and transportation of compressed, liquefied and dissolved gases (nitrogen, ammonia, argon, butane, butylene, hydrogen, air, helium, oxygen, xenon) at temperatures from 223 to $333 \mathrm{~K}$. There are no specific requirements for the design and materials of cylinders intended specifically for 
storing hydrogen. Hydrogen cylinders differ only in their green color. Specific steel grades recommended for the manufacture of cylinders are not given in [44], but the requirements for their required mechanical properties are presented. In practice, steels $45,30 \mathrm{KhGSA}$, and $38 \mathrm{KhL}$ are most often used as materials for these cylinders after the necessary heat treatment.

A similar picture takes place in the case of cylinders designed for high hydrogen pressures (up to $24.5 \times 10^{6} \mathrm{~Pa}$ ) [45], and in this case, there are no specific requirements for the design and materials of cylinders intended for hydrogen storage.

GOST 33260-2015 [82] provides the basic requirements for materials used for the manufacture of pipeline fittings intended for installation on pipelines transporting various working media, including hydrogen-containing ones. In terms of recommendations for the use of metallic materials in a hydrogen-containing environment, only the maximum allowable temperature of the structure is regulated depending on the steel grade and the partial pressure of the hydrogen-containing medium. In particular, in accordance with [82], at operating temperatures of gas pipelines (up to $313 \mathrm{~K}$ ), the steels presented in Table 11 are recommended as materials for their manufacture. There are also brands of their foreign analogs.

Table 11. Steels recommended for use in hydrogen-containing media at temperatures up to $463 \mathrm{~K}$ and pressures up to $40 \mathrm{MPa}$ [83].

\begin{tabular}{|c|c|}
\hline Steel According to GOST, TU, and Chemical Composition, \% & $\begin{array}{l}\text { Analog According to ASTM, AISI, API, DIN/EN, and } \\
\text { Chemical Composition, } \%\end{array}$ \\
\hline & \\
\hline $\begin{array}{r}\text { (C 0.17-0.24; Si 0.17-0.37; Mn } 0 . \\
\text { Ni 0.25; Cr } 0\end{array}$ & $\begin{array}{r}\text { (C 0.3; Si 0.15-0.3; Mn } 0 . \\
\text { Ni 0.4; }\end{array}$ \\
\hline & \\
\hline (C 0.12-0.18; Si 0.4-0.7 & (C 0.3; Si 0.15- \\
\hline 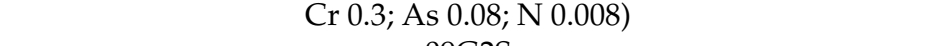 & $\mathrm{Nb}$ \\
\hline & \\
\hline $\begin{array}{r}\text { (C 0.12; Si } 0.5-0.8 ; \text { Mn } 1.3-1.7 ; \\
\text { As } 0.0\end{array}$ & $\begin{array}{r}(\mathrm{C} \text { 0.2; } \mathrm{Si} 0.2-0.35 ; \mathrm{M} \\
\mathrm{Nb} 0.02 ; \mathrm{P} 0.0\end{array}$ \\
\hline & \\
\hline $\begin{array}{r}\text { (C 0.11-0.18; Si } 0.17-0.3 \\
\text { P } 0.0\end{array}$ & (C 0.05-0.15; Si 0.5-1.0; $\mathrm{P}$ \\
\hline (C 0.15; Si 0.5; Mn 0.5; Cr 4.5-6.0; Mo & $\begin{array}{r}\text { ASTN } \\
\text { (C 0.15; Si 0.5; Mn 0.3-0.6; } \mathrm{C}\end{array}$ \\
\hline & \\
\hline $\begin{array}{r}\text { (C 0.08-0.15; Si 0.17-0.37; } 1 \\
\text { V } 0.1\end{array}$ & $\begin{array}{r}\text { (C 0.10-0.15; Si 0.15-0.35; } \\
\text { V 0.22-0.3; P }\end{array}$ \\
\hline S 0 & . \\
\hline & \\
\hline (C 0.08; Si 0.8; Mn 2.0; Cr 17.0-1 & $\begin{array}{r}\text { (C 0.08; Si 1.0; Mn 2.0; } \mathrm{Cr} 1 \\
\text { P } 0 .\end{array}$ \\
\hline & AS \\
\hline $\begin{array}{r}\text { (C 0.12; Si 0.8; Mn 2.0; Cr } 17.0- \\
\text { S } 0.0\end{array}$ & $\begin{array}{r}\text { (C 0.04-0.1; Si 1.0; Mn 2.0; } \\
\text { P } 0.0\end{array}$ \\
\hline 10 & El \\
\hline $.0-14.0 ;$ Mo 2.0-3.0; P 0.035; & (C 0.08; Si 1.0; Mn 2.0; Cr 16. \\
\hline & \\
\hline & A \\
\hline $\begin{array}{r}\text { (C 0.08; Si 0.8; } \mathrm{Mn} 2.0 ; \mathrm{Cr} \\
\text { Ti } 0.3-0\end{array}$ & $\begin{array}{r}\text { (C 0.08; Si 1.0; Mn 2.0; Cr } 16 \\
\text { Ti 0.7; P }\end{array}$ \\
\hline
\end{tabular}

As can be seen from the data in the table, for the manufacture of pipeline fittings for the transportation of hydrogen and its mixtures with other gases at a pressure of up to 
$40 \mathrm{MPa}$ and a temperature of normal operation (up to $323 \mathrm{~K}$ ), a wide range of carbon, low, medium, and high alloy steels can be used.

The normative documentation ASMEB31.12 [84] specifies the requirements for pipelines operating with gaseous and liquid hydrogen. This standard consists of Part GR-General Requirements, including General Requirements referenced by all other parts; Part IPIndustrial pipelines; Part PL-Piping, including distribution systems.

Part IP (Industrial Piping) regulations are designed for the hydrogen industry, including refineries, gas stations, chemical plants, power plants, semiconductor plants, cryogenic plants, hydrogen fuel instrumentation, and related facilities. This section recommends the use of materials (Table 12).

Table 12. Steel pipelines and component part IP [84].

\begin{tabular}{|c|c|c|c|c|}
\hline Number & Pipe Type & $\begin{array}{l}\text { Chemical Composition } \\
\text { (Limit Content), \% }\end{array}$ & \multicolumn{2}{|c|}{ Russian Analog } \\
\hline A105 & Carbon steel piping forgings & $\begin{array}{c}\text { C 0.35; Si 0.1-0.35; Mn 0.6-1.05; Cu 0.4; Ni 0.4; Cr 0.3; } \\
\text { Mo 0.12; V 0.08; P 0.035; S } 0.4\end{array}$ & \multicolumn{2}{|c|}{ Steel 20} \\
\hline \multirow{3}{*}{ A350 } & \multirow{3}{*}{$\begin{array}{l}\text { Carbon and low-alloy steel } \\
\text { forgings requiring impact testing } \\
\text { of pipeline components }\end{array}$} & \multirow{3}{*}{$\begin{array}{c}\text { For LF2 gradation: } \\
\text { C 0.3; Si 0.15-0.3; Mn 0.6-1.35; Mo 0.12; V 0.08; } \\
\text { Nb 0.02; Cu 0.4; Ni 0.4; Cr 0.3; } \\
\text { S 0.04; P } 0.035\end{array}$} & ASTM A350 LF1 & Steel 20 \\
\hline & & & ASTM A350 LF2 & 16GS \\
\hline & & & ASTM A350 LF3 & 09G2S \\
\hline \multirow{3}{*}{ A182 } & \multirow{3}{*}{$\begin{array}{l}\text { Forged or rolled alloy and } \\
\text { stainless-steel pipe flanges, } \\
\text { forged fittings, valves, and parts } \\
\text { for high-temperature service }\end{array}$} & \multirow{3}{*}{$\begin{array}{l}\text { For gradation F316: } \\
\text { C 0.08; Si 1.0; Mn 2.0; Cr 16.0-18.0; Ni 10.0-14.0; } \\
\text { Mo 2.0-3.0; P 0.045; S } 0.03\end{array}$} & ASTM A182 F11 & $15 \mathrm{KhM}$ \\
\hline & & & ASTM A182 F5 & 15Kh5M \\
\hline & & & ASTM A182 F316 & 08Kh18H10T \\
\hline A216 & $\begin{array}{l}\text { Fusion weldable carbon } \\
\text { steel castings for } \\
\text { high-temperature service }\end{array}$ & $\begin{array}{c}\text { For WCB grading: } \\
\mathrm{C}-0.3 ; \mathrm{Si}-0.6 ; \mathrm{Mn} 1.0 ; \mathrm{Cu}-0.3 ; \mathrm{Ni}-0.5 ; \mathrm{Cr}-0.5 ; \\
\mathrm{Mo}-0.2 ; \mathrm{V}-0.3 ; \mathrm{P}-\text { up to } 0.04 ; \mathrm{S}-\mathrm{up} \text { to } 0.045\end{array}$ & Steel 2 & \\
\hline
\end{tabular}

Part PL (Piping) rules apply to trunk pipelines, distribution pipelines and service lines used to transport hydrogen from the production facility to the end-use point. This section recommends the use of materials (Table 13).

Table 13. Pipeline steel parts PL [84].

\begin{tabular}{|c|c|c|c|}
\hline Number & Gradation & $\begin{array}{c}\text { Pipe Type and Yield Strength of } \\
\text { the Steel Used }\end{array}$ & Russian Analog \\
\hline A106 & B & $\begin{array}{c}\text { Seamless } 35,000 \text { psi (240 MPa) } \\
\text { (Grade B) }\end{array}$ & $\begin{array}{l}\text { Seamless hot-deformed steel } \\
\text { pipes in accordance with } \\
\text { GOST 8732-78 group B } \\
\text { (from steel 20) }\end{array}$ \\
\hline A333 & 6 & $\begin{array}{l}\text { Seamless with yield point 30,000 psi } \\
\text { (207 MPa) (grade A), 35,000 psi } \\
\text { (241 MPa) (grade B), 40,000 psi } \\
\text { (276 MPa) (grade C) }\end{array}$ & $\begin{array}{c}\text { For grade A: } \\
\mathrm{C}-0.25 ; \mathrm{Si}-0.1 ; \\
\mathrm{Mn}-0.27-0.93 ; \mathrm{P}-0.035 \\
\mathrm{~S}-0.45 ; \mathrm{Cu}-0.4 ; \mathrm{Ni}-0.4 \\
\mathrm{Cr}-0.4 ; \mathrm{Mo}-0.15 ; \mathrm{V}-0.08\end{array}$ \\
\hline
\end{tabular}

As can be concluded from Table 11, no significant difference was found between ASTM steels recommended by ASME B31.12 for hydrogen-containing media and GOST steels recommended by GOST 33260-2015 for hydrogen-containing media. Additionally, (see Tables 12 and 13) for pipes and components according to ASTM there are domestic analogs according to GOST, which is confirmed by the practice of interchangeability of pipeline components and pipes themselves according to ASTM with GOST for hydrogen-containing media at oil refining facilities with hydrogen facilities of such companies as "OJSC Mozyr oil refinery", PJSC "Rosneft Oil Company", LLC “Irkutsk oil company", etc. 


\section{Estimation of Losses during the Transportation of Compressed Hydrogen through the Pipeline Due to Gas Diffusion through the Pipe Wall}

Due to the smallness of hydrogen atoms $\left(\sim 0.5 \times 10^{-10} \mathrm{~m}\right)$, consisting of one proton and one electron, practically all metals are permeable to this gas [26,85]. In this regard, it seemed necessary to estimate the amount of hydrogen that can diffuse through the pipeline wall if compressed hydrogen is pumped through it. The assessment was carried out on the example of hydrogen transportation through a pipeline with a diameter of $1220 \mathrm{~mm}$, a wall thickness of $h=12 \mathrm{~mm}$, and a length of $L=40,000 \mathrm{~m}$ made of steel of strength class K42 (X52).

Initial data:

- $\quad$ pressure outside the pipe $P_{1}=0.1 \times 10^{6} \mathrm{~Pa}$ (atmospheric);

- $\quad$ pressure inside the pipe $P_{2}=10 \times 10^{6} \mathrm{~Pa}$;

- $\quad$ transportation temperature $T=298 \mathrm{~K}$;

- the diffusion coefficient of hydrogen in steel $D=4.32 \times 10^{-11} \mathrm{~m}^{2} / \mathrm{s}$ [86];

- the solubility of hydrogen in steel $S=5.9 \times 10^{-5} \mathrm{~m}^{3}$ gas $/\left(\mathrm{m}^{3}\right.$ solid $\left.{ }^{*} \mathrm{MPa}^{0.5}\right)$ [86].

It was assumed that at the initial moment of time the diffusion process proceeds in a non-stationary mode [28], in which the concentration distribution over the wall thickness changes with time in accordance with expression (2):

$$
\frac{c-c_{2}}{c_{0}-c_{2}}=1-\operatorname{erf}(x /(2 \cdot \sqrt{D t})) .
$$

where $c_{1} c_{2}$ is the hydrogen concentration inside the pipe wall at the point with the $x$ coordinate and on the inside of the wall, $\mathrm{m}^{3} / \mathrm{m}^{3} ; c_{0}$-hydrogen concentration inside the pipe wall at the initial moment of time (taken equal to 0 ), $\mathrm{m}^{3} / \mathrm{m}^{3} ; x$-coordinate along the pipe wall thickness, $\mathrm{m}$; $t$-coordinate in time, $\mathrm{s}$.

After the expiration of time $\tau_{0}$, a stationary regime is reached, in which the change in concentration along the wall thickness becomes constant and independent of time [25]. For this case, the hydrogen concentration at each point of the wall is (3)

$$
c=c_{1}+\frac{c_{2}-c_{1}}{h} x
$$

where $c_{1}$ is the hydrogen concentration on the outer side of the pipeline wall, $\mathrm{m}^{3} / \mathrm{m}^{3}$.

The time $\tau_{0}$ of the transition from one mode to another was estimated based on the empirical formula [87]:

$$
D=\frac{h^{2}}{6 \cdot \tau_{0}}
$$

where $\tau_{0}$ turned out to be equal to $555,556 \mathrm{~s}$ or 6.43 days.

The $c_{2}$ value for hydrogen, as for a diatomic gas, was determined by the Sieverts formula [88]:

$$
\mathrm{c}_{2}=S \cdot \sqrt{P}=0.000187 \mathrm{~m}^{3} / \mathrm{m}^{3}
$$

Then, in accordance with (2), the hydrogen concentration on the outer wall of the pipe $c_{1}$ by the time of transition to the stationary regime will be equal to $1.87 \times 10^{-5} \mathrm{~m}^{3} / \mathrm{m}^{3}$.

The results of calculating the concentration distribution are illustrated in Figure 12.

The volume of hydrogen diffusing through a unit surface during the time $\tau_{0}$ for a non-stationary diffusion mode was estimated by the Formula (6):

$$
q=(2 / \sqrt{\pi}) \cdot \sqrt{D \cdot t} \cdot\left(c_{2}-c_{0}\right)=1.033 \times 10^{-6} \mathrm{~m}^{3} / \mathrm{m}^{2}
$$

Hence, for the entire inner surface of the pipe $\left(F=300,587 \mathrm{~m}^{2}\right)$, the indicated volume of hydrogen leaks is $Q=0.31 \mathrm{~m}^{3}$. 


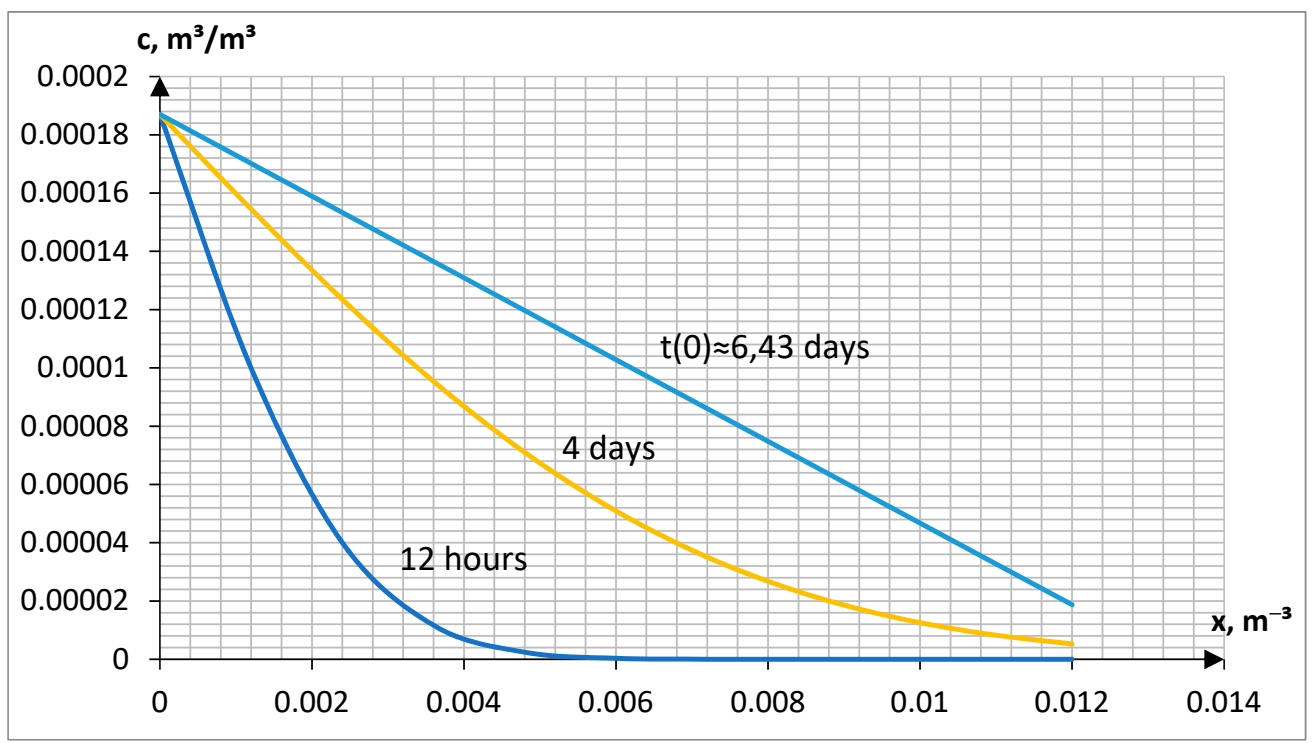

Figure 12. Distribution of hydrogen concentration over the pipe wall thickness under non-stationary and stationary modes at different moments of transportation (compiled by the authors).

For the stationary mode, the leakage volume was calculated through the diffusion flow

$$
J=-D \cdot S \frac{\sqrt{P_{2}}-\sqrt{P_{1}}}{\mathrm{H}}=-\Phi \frac{\sqrt{P_{2}}-\sqrt{P_{1}}}{\mathrm{H}}=6.05 \times 10^{-13} \mathrm{~m} / \mathrm{s}
$$

as

$$
Q=J \cdot F \cdot t
$$

which for the entire operation time of the pipeline (minus the time of non-stationary operation) was $230 \mathrm{~m}^{3}$.

Taking into account the volume of gas passed through the pipeline over 40 years of operation $\left(\mathrm{Q}=3.38\right.$ trillion $\left.\mathrm{m}^{3}\right)$, the loss of hydrogen due to its diffusion through the wall $\left(230 \mathrm{~m}^{3}\right)$ is less than $1 \times 10^{-5} \%$ of the volume of gas pumped and may not be taken into account during gas transport.

\section{Discussion}

In accordance with the above research results, the saturation of steels with hydrogen ("hydrogenation") is accompanied by a change in the mechanical properties of the metal, expressed in a decrease in the relative constriction $\Psi$, the relative elongation $\delta$, the fracture work $A_{p}$, the impact toughness of the $\mathrm{KC}$, the true breaking stress $S_{k}$, the tensile strength $\sigma_{B}$, and the hardness $\mathrm{HV}$, with an almost unchanged value of the yield strength $\sigma_{T}$ of steels. Especially at saturation, the plastic characteristics $\Psi, \delta$, and the true breaking stress $S_{k}$ are sharply reduced, as a result of which hydrogenation of a stressed steel structure can lead to its spontaneous destruction within a few hours. At the same time, the information found in the literature does not allow grading steels, including pipeline ones, in terms of resistance to hydrogenation and identifying the most resistant ones.

It is fundamental that the aforementioned saturation of steels with hydrogen in amounts that can cause a noticeable change in the properties of materials can occur only if there are significant amounts of hydrogen on the surface of the steel structure, which is, namely, in an atomic state and is able to penetrate into the metal due to diffusion. This can be achieved electrolytically or by holding structures in a hydrogen-containing environment at high temperatures and pressures.

At the same time, in the case of contact of a steel structure with gaseous hydrogen at a relatively low temperature, the limiting stage of the process of its penetration into steel is the dissociation of $\mathrm{H}_{2}$ molecules adsorbed on the metal surface. Since at temperatures typical 
for pipeline transport (up to $323 \mathrm{~K}$ ), the degree of dissociation of $\mathrm{H}_{2}$ molecules is negligible, the number of formed hydrogen atoms is also very insignificant even at a hydrogen gas pressure of tens and hundreds of MPa, significantly exceeding the gas pressure in pipelines. At the same time, the nature of the adsorbent (steel grade) does not fundamentally affect the degree of this dissociation. For this reason, cylinders for storing compressed hydrogen, made of carbon and low-alloy steels, regardless of their chemical composition, serve for decades in contact with high-pressure hydrogen without any noticeable changes in the mechanical properties of their material. The loss of compressed hydrogen due to its diffusion through the pipeline wall during its normal operation, regardless of the steel grade of the pipe material, is less than $1 \times 10^{-5} \%$ of the volume of the pumped gas and may not be taken into account when transporting gas.

Based on the presented literature data, it can be concluded that the elastic deformation of steel structures in contact with gaseous hydrogen or its mixtures does not significantly affect the intensity of the hydrogenation process and, as a consequence, the mechanical properties of the construction material. This conclusion is also confirmed by the already cited example of long-term operation of hydrogen cylinders, the material of the walls of which is under the influence of tensile stresses in the elastic region of deformations, which change during the operation of the cylinder as it is filled or emptied.

At the same time, according to the data presented, plastic deformation of steel structures in an atmosphere of gaseous $\mathrm{H}_{2}$ and its mixtures intensifies the process of saturation of structures with hydrogen, accompanied by a decrease in the strength and plastic properties of the material of structures. Moreover, this negative effect is observed even at very low concentrations $(\sim 0.1 \%)$ of hydrogen in the mixture. It can be assumed that this effect is associated with the formation of a juvenile metal surface during plastic deformation, which has an increased ability to adsorb hydrogen molecules and transform them into an atomic state.

Thus, we can conclude that when steel pipelines operate to pump compressed hydrogen or its mixtures at temperatures close to normal and only in the area of elastic deformations of their wall, the pipeline material, regardless of the grade of the pipeline steel used and the pressure in the pipe, should not be sensitive to the effects of hydrogen. At the same time, due to pressure pulsations in the pipeline, its metal, in contrast to the material of the cylinder, will be subjected to repeated cyclic loads, even in the region of elastic deformations [89], information on the effect of which on the behavior of steels in hydrogen was not found by the authors. On the other hand, due to possible soil movement or other reason [90], plastic deformation of the pipe material in a local place of the underground pipeline cannot be ruled out, which can cause hydrogen saturation, the negative consequences of which will be different for different grades of pipeline steel. In this regard, the question of how much this or that pipeline steel degrades its mechanical properties during plastic deformation in a compressed hydrogen environment also requires study. A special place here is occupied by the study of the effect of dissolved hydrogen on the mechanical properties of the metal of welded joints. The question also requires experimental verification-will the process of hydrogen saturation intensify if the pipe wall is under stress due to the presence of cathodic protection of the pipeline?

\section{Conclusions}

1. Diffusion of hydrogen into steel is carried out only in its atomic state and, since at normal temperature the degree of dissociation of hydrogen molecules is negligible, gaseous hydrogen at this temperature even at high pressures into steel, regardless of its grade, practically does not penetrate and has no noticeable negative impact on its mechanical properties. This conclusion is confirmed by the experience of long-term trouble-free operation of cylinders for storing compressed hydrogen, made of carbon and low-alloy steels of a wide range of names. 
2. Losses during the transportation of compressed hydrogen through the main pipeline due to gas diffusion through the pipe wall are millionths of a percent of the volume of the pumped gas and may not be taken into account in the calculations.

3. Elastic deformation of steel structures in contact with gaseous hydrogen or its mixtures does not noticeably affect the intensity of the hydrogen saturation of their material and, as a consequence, its mechanical properties.

4. Plastic deformation of steel structures in an atmosphere of gaseous $\mathrm{H}_{2}$ and its mixtures intensifies the process of saturation of structures with hydrogen, accompanied by a decrease in the strength and plastic properties of the material of the structures. Moreover, this negative effect is observed even at very low concentrations $(\sim 0.1 \%)$ of hydrogen in the mixture.

5. Among the factors that require further study in order to develop a conclusion on the possibility of transporting compressed hydrogen through a particular pipeline, the following can be indicated:

- the effect of multiple cyclic loads in the pipeline on the behavior of its material in hydrogen, i.e., determination of the fatigue strength of pipeline steels in a hydrogen-containing environment;

- the degree of deterioration of the mechanical characteristics of various pipeline steels, including in the form of welded joints, when they are saturated with hydrogen;

- the effect of cathodic protection on the intensity of hydrogenation of pipeline steels in contact with the compressed hydrogen state.

Author Contributions: Conceptualization, V.I.B.; methodology, V.I.B.; validation, V.I.B., G.V.B. and Y.V.M.; formal analysis, G.G.P.; investigation, I.U.L.; resources, V.I.B.; writing-original draft preparation, I.U.L.; writing-review and editing, V.I.B., I.U.L., G.G.P. and Y.V.M.; visualization, I.U.L.; supervision, V.I.B. and G.V.B.; project administration, V.I.B. and G.V.B.; funding acquisition, G.V.B. All authors have read and agreed to the published version of the manuscript.

Funding: The research was performed at the expense of the subsidy for the state assignment in the field of scientific activity for 2021 NoFSRW-2020-0014.

Institutional Review Board Statement: Not applicable.

Informed Consent Statement: Not applicable.

Conflicts of Interest: The authors declare no conflict of interest. The funders had no role in the design of the study; in the collection, analyses, or interpretation of data; in the writing of the manuscript, or in the decision to publish the results.

\section{References}

1. Ivanova, I.V.; Shaber, V.M. Modern perspectives of gas production. J. Min. Inst. 2016, 219, 403-411.

2. Litvinenko, V.S.; Shuvalov, Y.V.; Nikulin, A.N.; Gasparyan, N.A.; Smirnov, Y.D.; Kamenskiy, A.A. New technologies for ensuring safety in mining in Russia. J. Min. Inst. 2007, 172, 178-185.

3. United Nations. FCCC/CP/2015/L.9/Rev.1 Adoption of the Paris Agreement. In Proceedings of the Conference of the Parties, Paris, France, 30 November-11 December 2015.

4. United Nations. FCCC/INFORMAL/84 GE.05-62220 (E) 200705 United Nations Framework Convention on Climate Change; UN: New York, NY, USA, 1994. Available online: https:/ / unfccc.int/documents/36938 (accessed on 23 July 2021).

5. Order No. 2634-r Action Plan. Development of Hydrogen Energy in the Russian Federation until 2024. Moscow. 2020. Available online: http:/ / government.ru/docs/40703/ (accessed on 23 July 2021).

6. ISO, T. R 15916: Basic Considerations for the Safety of Hydrogen Systems; ISO: Geneva, Switzerland, 2015.

7. National Aeronautics; Space Administration. Safety Standard for Hydrogen and Hydrogen Systems; Office of Safety and Mission Assurance: Washington, DC, USA, 2005.

8. Alekseeva, O.K.; Kozlov, S.I.; Fateev, V.N. Hydrogen transporter. Altern. Fuel 2011, 21, 18-24.

9. Kozlov, S.I.; Fateev, V.N. Hydrogen Energy: Current State, Problems, Prospects; Gazprom VNIIGAZ: Moscow, Russia, 2009.

10. Simbek, D.R.; Chang, E. Hydrogen Supply: Cost Estimate for Hydrogen Pathways-Scoping Analysis; National Renewable: Golden, CO, USA, 2002.

11. Hamburg, Y.D.; Semenov, V.P.; Dubovkin, M.F.; Smirnova, L.N. Hydrogen. Properties, Receipt, Storage, Transportation, Application; Publishing House “Chemistry”: Moscow, Russia, 1989; p. 672. 
12. Qiu, Y.; Yang, H.; Tong, L.; Wang, L. Research progress of cryogenic materials for storage and transportation of liquid hydrogen. Metals 2021, 11, 1101. [CrossRef]

13. Freedom CAR \& Fuel Partnership. Hydrogen Delivery Technology Roadmap; DOE: Washington, DC, USA, 2005.

14. Alekseeva, O.K.; Kozlov, S.I.; Samsonov, R.O.; Fateev, V.N. Hydrogen storage systems. Altern. Fuel 2009, 10, 68-74.

15. PJSC. Cryogenmash, Hydrogen Equipment. GK Softbalans. Available online: https://cryogenmash.ru/catalog/vodorodnoeoborudovanie/ (accessed on 14 May 2021).

16. Kuzmenko, I.F.; Rumyantsev, Y.N.; Saidal, G.I. Modern trends in the design and manufacture of tanks for storage and transportation of liquid hydrogen. Ind. Gases 2008, 53-58.

17. Litvinenko, V.S.; Tsvetkov, P.S.; Dvoinikov, M.V.; Buslaev, G.V. Barriers to the implementation of hydrogen initiatives in the context of sustainable development of global energy. J. Min. Inst. 2020, 244, 428-438. [CrossRef]

18. Ma, J.; Liu, S.; Zhou, W.; Pan, X. Comparison of hydrogen transportation methods for hydrogen refueling station. J. Tongji Univ. Nat. Sci. 2008, 36, 615-619.

19. Fortov, V.E.; Makarov, A.A.; Mitrova, T. Global energy security: Problems and solutions. Her. Russ. Acad. Sci. 2007, 77, 7-14. [CrossRef]

20. Korobtsev, S.V.; Fateev, V.N.; Samsonov, R.O.; Kozlov, S.I. Safety of hydrogen energy. Altern. Fuel 2008, 5, 68-72.

21. André, J.; Auray, S.; De Wolf, D.; Memmah, M.M.; Simonnet, A. Time development of new hydrogen transmission pipeline networks for France. Int. J. Hydrog. Energy 2014, 39, 10323-10337. [CrossRef]

22. Messaoudani, Z.L.; Rigas, F.; Hamid, M.D.B.; Hassan, C.R.C. Hazards, safety and knowledge gaps on hydrogen transmission via. natural gas grid: A critical review. Int. J. Hydrog. Energy 2016, 41, 17511-17525. [CrossRef]

23. Guy, P.; Laszlo, T.; Julien, C. Effects of hydrogen addition on design, maintenance and surveillance of gas networks. Processes 2021, 9, 1219. [CrossRef]

24. Litvinenko, V. The role of hydrocarbons in the global energy agenda: The focus on liquefied natural gas. Resources 2020, 9, 59. [CrossRef]

25. Birnbaum, H.K. An overview of hydrogen failure mechanisms. Nav. Res. 1997, 30, 19-34.

26. Moroz, L.S.; Chechulin, B.B. Hydrogen Fragility of Metals; Metallurgiya: Moscow, Russia, 1967.

27. Li, Y.; Zhang, K.; Lu, D.; Zeng, B. Hydrogen-assisted brittle fracture behavior of low alloy 30CrMo steel based on the combination of experimental and numerical analyzes. Materials 2021, 14, 21.

28. Fromm, E.; Gebhardt, E. Gases and Carbon in Metals; Linchevsky, B.V., Ed.; Metallurgiya: Moscow, Russia, $1980 ;$ p. 712.

29. Khrustalev, Y.A. Flooding of Steel as a Consequence of its Destruction; Vestnik TSU: Tomsk, Russia, 2000.

30. Moroz, L.S.; Mingin, T.E. Investigation of the mechanism of hydrogen brittleness of steel. Rep. USSR Acad. Sci. 1965, 11, 311-313.

31. Sorokin, V.G.; Volosnikov, V.G.; Vyatkin, S.A. Marochnik Steels and Alloys; Sorokin, V.G., Ed.; Mashinostroenie: Moscow, Russia, $1989 ;$ p. 640.

32. Kolachev, B.A. Hydrogen Fragility of Metals; Metallurgy: Moscow, Russia, 1985.

33. Morozov, A.N. Hydrogen and Nitrogen in Steel, 2nd ed.; Metallurgy: Moscow, Russia, 1968.

34. Chengshuang, Z.; Baoguo, Y.; Yangyang, S.; Tiancheng, C.; Peng, X.; Lin, Z. Effects of internal hydrogen and surface-absorbed hydrogen on the hydrogen embrittlement of X80 pipeline steel. Int. J. Hydrogen Energy 2019, 44, 22547-22558.

35. Michler, T.; Wackermann, K.; Schweizer, F. Review and assessment of the effect of hydrogen gas pressure on the embrittlement of steels in gaseous hydrogen environment. Metals 2021, 11, 637. [CrossRef]

36. Boot, T.; Riemslag, T.; Reinton, E.; Liu, P.; Walters, C.L.; Popovich, V. In-Situ hollow sample setup design for mechanical characterization of gaseous hydrogen embrittlement of pipeline steels and welds. Metals 2021, 11, 1242. [CrossRef]

37. Trautmann, A.; Mori, G.; Oberndorfer, M.; Bauer, S.; Holzer, C.; Dittmann, C. Hydrogen uptake and embrittlement of carbon steels in various environments. Materials 2020, 13, 3604. [CrossRef]

38. Michler, T.; Schweizer, F.; Wackermann, K. Review on the influence of temperature upon hydrogen effects in structural alloys. Metals 2021, 11, 423. [CrossRef]

39. Guzmán, A.A.; Jeon, J.; Hartmaier, A.; Janisch, R. Hydrogen embrittlement at cleavage planes and grain boundaries in bcc iron-revisiting the first-principles cohesive zone model. Materials 2020, 13, 5785. [CrossRef]

40. Zamotorin, M.I.; Kosovtseva, T.S. The Collection of Metallurgy; AN USSR: Kyiv, Ukraine, 1957; p. 77.

41. Beilinova, T.A.; Storozhenko, I.A.; Vasilenko, E.N.; Dudnik, A.F.; Feiglin, V.N. The influence of long-term storage of hydrogen on the properties of high-pressure cylinders. Met. Sci. Heat Treat. Met. 1993, 3, 29-31.

42. Storozhenko, I.A. Selection of Steel and Optimization of Heat Treatment Modes for Lightweight High-Pressure Cylinders for Storage and Transportation of Gaseous Hydrogen Based on the Study of Material Resistance against Hydrogen Embrittlement, Dnepropetrovsk, 1995.

43. Matorin, V.I.; Ovsanikov, B.M.; Chromov, V.D.; Birun, N.A.; Minashin, A.V.; Petrenko, E.D.; Chebotarev, V.I.; Zhembus, M.F.; Geshelin, V.G.; Bogacheva, A.V. GOST 1497-84. Metals. Tensile Test Methods; Standartinform: Moscow, Russia, 1986.

44. GOST 949-73 Steel Cylinders of Small and Medium Volume for Gases at P. Available online: https://auremo.biz/gosts/gost-94973.html (accessed on 25 July 2021).

45. GOST 9731-79 Seamless Steel Cylinders of Large Volume for Gases at P. Available online: https://auremo.biz/gosts/gost-9731-7 9.html (accessed on 25 July 2021).

46. TU 14-3-883-79 Steel Cylinders with a Volume of 400 Liters with a Working Pressure of $400 \mathrm{kgf} / \mathrm{cm}^{2}$. 1980. Available online: https:/ / www.hitachicm.eu/wp-content/uploads/2018/06/KA-EN273EU.pdf (accessed on 25 July 2021). 
47. GOST 9454-78 Impact Bending Test Method at Low, Room and High Temperatures. 1979. Available online: https://auremo.biz/ gosts / gost-9454-78.html (accessed on 25 July 2021).

48. Cho, L.; Kong, Y.; Speer, J.; Findley, K. Hydrogen embrittlement of medium mn steels. Metals 2021, 11, 358. [CrossRef]

49. Chugunov, A.V.; Bebeshko, I.G.; Semenov, A.M.; Becker, V.; Fenin, K.; Hecher, T. Experimental study of the effect of a mixture of methane and hydrogen gases on the structural and mechanical properties of some steel grades. Gas Ind. 2016, 10, 82-89.

50. Gressner, A.M.; Gressner, O.A. Deutsches Institut fur Normung eV (DIN). In Metallic Materials-Tensile Testing-Part 1: Method of Test at Room Temperature; Springer: Berlin/Heidelberg, Germany, 2020.

51. ISO; EN. Metallic Materials-Charpy Pendulum Impact Test-Part 1: Test Method; ISO: Geneva, Switzerland, 2017.

52. ISO; EN. Metallic Materials-Vickers Hardness Test-Part 2: Verification and Calibration of Testing Machines; ISO: Geneva, Switzerland, 2018.

53. Nguyen, T.T.; Park, J.S.; Kim, W.S.; Nahm, S.H.; Beak, U.B. Environment hydrogen embrittlement of pipeline steel X70 under various gas mixture conditions with In Situ small punch tests. Mater. Sci. Eng. A 2020, 781, 139114. [CrossRef]

54. Artola, G.; Aldazabal, J. Hydrogen assisted fracture of 30MnB5 high strength steel: A case study. Metals 2020, 10, 1613. [CrossRef]

55. Taraban, V.V.; Yu, V.P. Optimization of impact fracture of materials with cracks. J. Min. Inst. 2005, 165, 188-190.

56. Sidorenko, L.A.; Efimenko, L.A.; Yu, S.I.; Ya, A.S. Evaluation of the degree of hydrogen embrittlement of low-carbon steels. Int. Sci. J. Altern. Energy Ecol. 2004, 9, 22-25.

57. Robertson, I.M.; Sofronis, P.; Nagao, A.; Martin, M.L.; Wang, S.; Gross, D.W.; Nygren, K.E. Hydrogen embrittlement understood. Metall. Mater. Trans. B 2015, 46, 1085-1103. [CrossRef]

58. Dadfarnia, M.; Novak, P.; Ahn, D.C.; Liu, J.B.; Sofronis, P.; Johnson, D.; Robertson, I.M. Recent advances in the study of structural materials compatibility with hydrogen. Adv. Mater. 2010, 22, 1128-1135. [CrossRef] [PubMed]

59. Sofronis, P.; Robertson, I.M.; Johnson, D.D., III. Hydrogen Embrittlement of Pipelines Steels: Fundamentals, Experiments, Modeling; DOE Hydrogen Pipeline Working Group Worshop: Washington, DC, USA, 2007; pp. 296-301.

60. Colás, R.; Totten, G.E. Encyclopedia of Iron, Steel, and Their Alloys; Taylor \& Francis Group: Abington, PA, USA, 2016.

61. Tetelman, A.; Robertson, W. Direct observation and analysis of crack propagation in iron-3\% silicon single crystals. Acta Met. 1963, 11, 415-426. [CrossRef]

62. Tromans, D. On surface energy and the hydrogen embrittlement of iron and steels. Acta Met. Mater. 1994, 42, $2043-2049$. [CrossRef]

63. Lynch, S. Hydrogen embrittlement phenomena and mechanisms. Corros. Rev. 2012, 30, 105-123. [CrossRef]

64. Gangloff, R.P.; Somerday, B.P. Gaseous Hydrogen Embrittlement of Materials in Energy Technologies; Woodhead Publishing Limited: Cambridge, UK, 2012.

65. Birnbaum, H.K.; Robertson, I.M.; Sofronis, P. Hydrogen effects on plasticity. In Multiscale Phenomena in Plasticity: From Experiments to Phenomenology, Modelling and Materials Engineering; Springer Science and Business Media: Berlin/Heidelberg, Germany, 2000; Volume 19, pp. 367-381.

66. Nagumo, M. Mechanism of hydrogen-related failure I. Zair. Kankyo 2007, 56, 343-352. [CrossRef]

67. Nagumo, M. Mechanism of hydrogen-related failure II. Zair. Kankyo 2007, 56, 382-394. [CrossRef]

68. Song, J.; Curtin, W. A nanoscale mechanism of hydrogen embrittlement in metals. Acta Mater. 2011, 59, 1557-1569. [CrossRef]

69. Song, J.; Curtin, W.A. Atomic mechanism and prediction of hydrogen embrittlement in iron. Nat. Mater. 2012, 12, 145-151. [CrossRef]

70. Birnbaum, H. Mechanical properties of metal hydrides. J. Less Common Met. 1984, 104, 31-41. [CrossRef]

71. Eliezer, D.; Chakrapani, D.G.; Altstetter, C.J.; Pugh, E.N. The influence of austenite stability on the hydrogen embrittlement and stress-corrosion cracking of stainless steel. Met. Mater. Trans. A 1979, 10, 935-941. [CrossRef]

72. Kirchheim, R. On the solute-defect interaction in the framework of a defactant concept. Int. J. Mater. Res. 2009, 100, 483-487. [CrossRef]

73. Samigullin, G.H.; Schipachev, A.M.; Samigullina, L.G. International conference. Complex equipment of quality control laboratories. J. Phys. Conf. Ser. 2018, 1118, 012035.

74. Shin, H.-S.; Kim, K.-H.; Baek, U.-B.; Nahm, S.-H. Development of evaluation technique for hydrogen embrittlement behavior of metallic materials using In-Situ sp testing under pressurized hydrogen gas conditions. Trans. Korean Soc. Mech. Eng. A 2011, 35, 1377-1382. [CrossRef]

75. Kenichi, K.; Takao, M.; Toshirou, A.; Iwase, A.; Hiroyuki, I. Effect of hydrogen partial pressure on the hydrogen embrittlement susceptibility of type 304 stainless steel in high pressure H2/ Ar mixed gas. ISIJ Int. 2015, 55, 2477-2482.

76. Michihiko, N. Fundamentals of Hydrogen Embrittlement; Springer: Singapore, 2016.

77. Blagoeva, D.; Hurst, R. Application of the CEN (European Committee for Standardization) small punch creep testing code of practice to a representative repair welded P91 pipe. Mater. Sci. Eng. A 2009, 510-511, 219-223. [CrossRef]

78. García, T.E.; Rodríguez, C.; Belzunce, F.J.; Suárez, C. Estimation of the mechanical properties of metallic materials by means of the small punch test. J. Alloy. Compd. 2014, 582, 708-717. [CrossRef]

79. García, T.E.; Rodríguez, C.; Belzunce, F.J.; Cuesta, I.I. Effect of hydrogen embrittlement on the tensile properties of CrMoV steels by means of the small punch test. Mater. Sci. Eng. A 2016, 664, 165-176. [CrossRef]

80. Slifka, A.J.; Drexler, E.S.; Nanninga, N.E.; Levy, Y.S.; McColskey, J.D.; Amaro, R.L.; Stevenson, A.E. Fatigue crack growth of two pipeline steels in a pressurized hydrogen environment. Corros. Sci. 2014, 78, 313-321. [CrossRef] 
81. ASTM International. ASTM E647-05 Standard Test Method for Measurement of Fatigue Crack Growth Rates; American Society for Testing and Materials: Conshohocken, PA, USA, 2005.

82. GOST 33260-2015. Pipe Fittings. Metals Used in Valve Construction. Basic Requirements for the Choice of Materials; Standartinform: Moscow, Russia, 2015.

83. GOST 32569-2013. Steel Technological Pipelines. Requirements for the Device and Operation at Explosive and Fire Hazardous and Chemically Hazardous Industries; Standartinform: Moscow, Russia, 2015.

84. ASME B31.12-2019. Hydrogen Piping and Pipelines. Available online: https://www.madcad.com/store/package/ASME-B31.12 (accessed on 25 July 2021).

85. Schefer, R.; Houf, W.; Marchi, C.S.; Chernicoff, W.; Englom, L. Characterization of leaks from compressed hydrogen dispensing systems and related components. Int. J. Hydrogen Energy 2006, 31, 1247-1260. [CrossRef]

86. Zahreddine, H.; Manoranjan, M.; Sami, E. Hydrogen embrittlement of steel pipelines during transients. In Proceedings of the 22nd European Conference on Fracture-ECF22, Loading and Environmental effects on Structural Integrity, Belgrade, Serbia, 26-31 August 2018.

87. Cherepovitsev, Y.; Chernov, I.; Tyurin, I. Methods for Studying Metal-Hydrogen Systems: A Textbook; TPU Publishing House: Tomsk, Russia, 2008; p. 286.

88. Kazakov, A.A.; Ryaboshuk, S.V. Physicochemical Foundations of Steel-Smelting Processes; Polytechnic University: St. Petersburg, Russia, 2013; p. 44.

89. Lisin, Y.V.; Neganov, D.A.; Surikov, V.I.; Gumerov, M.K. Research of changes of pipeline metal properties during operation: Summary of results and prospective developments of Ufa scholarly tradition. Oil Oil Prod. Pipeline Transp. Sci. Technol. 2017, 7, 22-30. [CrossRef]

90. Nikolaev, A.K.; Dokukin, V.P.; Putikov, O.F. Method of laying an underground pipeline in areas with increased seismicity. J. Min. Inst. 2012, 199, 354-356. 